\title{
A Review of Current Research into the Biogenic Synthesis of Metal and Metal Oxide Nanoparticles via Marine Algae and Seagrasses
}

\author{
Derek Fawcett, ${ }^{1}$ Jennifer J. Verduin, ${ }^{2}$ Monaliben Shah, ${ }^{1}$ \\ Shashi B. Sharma, ${ }^{3}$ and Gérrard Eddy Jai Poinern ${ }^{1}$ \\ ${ }^{1}$ Murdoch Applied Nanotechnology Research Group, Department of Physics, Energy Studies and Nanotechnology, \\ School of Engineering and Energy, Murdoch University, Murdoch, WA 6150, Australia \\ ${ }^{2}$ School of Veterinary and Life Sciences, Environmental \& Conservation Sciences Murdoch University, Murdoch, WA 6150, Australia \\ ${ }^{3}$ Department of Agriculture and Food, 3 Baron Hay Court, South Perth, WA 6151, Australia
}

Correspondence should be addressed to Gérrard Eddy Jai Poinern; g.poinern@murdoch.edu.au

Received 7 June 2016; Revised 28 November 2016; Accepted 28 November 2016; Published 9 January 2017

Academic Editor: Kalimuthu Kalishwaralal

Copyright (C) 2017 Derek Fawcett et al. This is an open access article distributed under the Creative Commons Attribution License, which permits unrestricted use, distribution, and reproduction in any medium, provided the original work is properly cited.

\begin{abstract}
Today there is a growing need to develop reliable, sustainable, and ecofriendly protocols for manufacturing a wide range of metal and metal oxide nanoparticles. The biogenic synthesis of nanoparticles via nanobiotechnology based techniques has the potential to deliver clean manufacturing technologies. These new clean technologies can significantly reduce environmental contamination and decease the hazards to human health resulting from the use of toxic chemicals and solvents currently used in conventional industrial fabrication processes. The largely unexplored marine environment that covers approximately $70 \%$ of the earth's surface is home to many naturally occurring and renewable marine plants. The present review summarizes current research into the biogenic synthesis of metal and metal oxide nanoparticles via marine algae (commonly known as seaweeds) and seagrasses. Both groups of marine plants contain a wide variety of biologically active compounds and secondary metabolites that enables these plants to act as biological factories for the manufacture of metal and metal oxide nanoparticles.
\end{abstract}

\section{Introduction}

In recent years a convergence between biological based technologies, green chemistry, and nanotechnology has taken place. The objective of this convergence is to create new materials and manufacturing processes that reduce or eliminate the use of hazardous substances [1]. An important aspect of nanotechnology is the synthesis of nanometer scale materials and the direct control of particle morphology and dimensions during formation. Nanometer scale materials have at least one dimension less than $100 \mathrm{~nm}$ and can have a wide variety of geometric shapes such as plates, sheets, tubes, wires, and particles. Numerous studies have shown that nanometer scale materials exhibit unique chemical, physical, electronic, optical, thermal, mechanical, and biological properties that significantly differ from their bulk scale counterparts $[2,3]$. These unique properties result from the extremely small size, shape, and size distribution. In addition, because of their small size, nanomaterials can act as bridge between bulk scale materials and molecular structures [4]. In terms of composition, nanomaterials can be broadly classified into two types, namely, organic and inorganic. Organic nanomaterials are carbon based, while inorganic nanomaterials include noble metals (gold, platinum, and silver), magnetic materials (iron oxide $\mathrm{Fe}_{3} \mathrm{O}_{4}$ ), and semiconductors such as titanium dioxide and zinc oxide.

The physiochemical properties of bulk scale materials are largely understood and recent discoveries have focused on materials existing in the region between the atomic scale and the much larger bulk scale. These discoveries arise from the significant increase in the surface area to volume ratio when bulk scale materials are reduced into much smaller amounts. The larger surface area to volume ratio found in nanometer scale materials is the major contributing factor 
that influences the physiochemical properties [5]. Thus, at the nanometer scale there are significant changes in both surface chemistry and chemical reactivity [6]. These unique and novel size-dependent properties have led to nanoparticles being promoted for a wide range of applications. Typical applications include biosensors [7, 8], catalysts [9-11], environmental remediation [12-14], labelling for immunoassays $[15,16]$, hyperthermia treatment of tumors [17-19], antibacterial drugs [20,21], and vector delivery of therapeutic drugs for cancer treatments [22-24]. However, studies have also shown the properties of manufactured nanoparticles are heavily dependent on specific parameters such as particle size, morphology, and size distribution [25]. Consequently, it is very important to control both particle size and shape during manufacture. Thus, effective control during production enables the customization of nanoparticles for specific applications.

The manufacture of nanoparticles can be broadly defined into two approaches. The first is the top down approach and involves a material undergoing significant size reduction via physical or chemical processes $[26,27]$. During size reduction, the resulting particle size, shape, and surface structure are heavily dependent on the technique used. Unfortunately, size reduction also tends to introduce surface imperfections that can significantly impact the overall physicochemical properties of the fabricated nanoparticle. The second, bottom up approach builds nanoparticles via the assembly of atoms, molecules, and smaller particles or monomers [28, 29]. Unfortunately, many of the chemical and physical processes used in both approaches suffer from several drawbacks such as low material conversion rates, are technically complex, have high energy requirements, and are generally expensive. Furthermore, many of these processes employ hazardous chemicals such as reducing agents, organic solvents, and nonbiodegradable stabilizing agents. For example, processes such as chemical precipitation and pyrolysis often result in toxic chemical species being deposited on the surface of newly formed nanoparticles. The presence of surface contaminants makes these nanoparticles unsuitable for clinical and biomedical applications [30, 31]. Because of the drawbacks associated with conventional manufacturing processes there has been a growing interest in developing new ecofriendly production technologies based on the principles of green chemistry [32]. Accordingly, research in recent years has focused on manufacturing nanomaterials via nanotechnology-based processes that promote the principles green chemistry and reduce or totally eliminate the use of hazardous chemicals. Thus, ecofriendly green nanotechnology-based processes for the manufacture of nanoparticles have attracted considerable interest worldwide [33, 34]. To emphasise this alternative approach, recent research has focused on using biological entities to synthesize a wide variety of nanoparticles. Biosynthesis via unicellular and multicellular biological entities such as actinomycetes [35], bacteria [36], fungus [37], marine algae [38], plants [39], viruses [40], and yeast [41] offer alternative ecofriendly approaches for producing nanoparticles. Each of these biological entities, to varying degrees, can perform as natural biofactories for producing particular nanoparticles. Each of the biological entities has active molecules and compounds that can act as reducing agents and stabilizing agents to synthesize nanoparticles with diverse sizes, shapes, compositions, and physicochemical properties [42].

The biologically diverse marine environment covers around $70 \%$ of the earth's surface and is largely unexplored. Recent studies have shown that several marine plants have the ability to perform as biofactories for the production of nanoparticles $[43,44]$. In particular, interest in producing new and effective medicines from natural marine plant sources has revealed that several forms of marine algae [45] have the potential to produce a variety of nanoparticles. A number of these nanoparticle types have been found to be effective antimicrobial agents [46, 47]. Marine algae contains a diverse range of different species, which are generally classified into two groups, namely, microalgae and macroalgae. Microalgae species such as phytoplankton survive suspended in the water column, while macroalgae (commonly known as seaweed) are plant-like organisms that can range in size from a few centimeters up to several meters in length. For example, the giant kelp grows up from the seafloor to form vast underwater forests. Seaweeds have adapted to living in a variety of habitat, ranging from small tidal rock pools close to shore or living several kilometers offshore in seawater depths capable of receiving sufficient light to promote photosynthesis. Algae are broadly classified into three groups based on the algal body or thallus pigmentation. The color groups are brown algae (phaeophytes), green algae (chlorophytes), and red algae (rhodophytes) [48]. Brown and red algae are predominantly marine based, with some species of red algae being found in water depths where light levels are extremely low, while green algae is found in both marine and freshwater environments. Figure 1 presents a selection of marine algae and seagrasses found in coastal waters along the West Australian coastline.

Since the dawn of time, the combined effects of tides and wave action have resulted in large quantities of seaweed being washed up beaches and shorelines in many parts of the world. Consequently, for many centuries coastal communities have consumed seaweed as a nutritional supplement to their diets and as an ingredient in medicinal remedies. Even today, seaweed is a staple food source and medicinal remedy in daily use throughout South-East Asia and Japan $[49,50]$. Several studies have revealed that seaweeds are a rich source of biologically active compounds such as carbohydrates, carotenoids, polysaccharides, proteins, vitamins, and numerous secondary metabolites [51-53]. The studies have also shown the active compounds present in seaweeds have medicinal properties that can be used in conventional treatments and alternative therapies [51,54-56]. Studies have also shown seaweed extracts can have both anti-inflammatory and inhibitory properties that can be used to treat various medical conditions and suppress some forms of cancer [57-60]. In addition, seaweeds are also capable of accumulating heavy metals [61] and the secondary metabolites of several types of seaweed have anti-biological fouling properties [62]. Furthermore, recent studies have reported the biological reduction of metal ions in aqueous based seaweed solutions [36, 6365]. These recent studies have confirmed that the various 


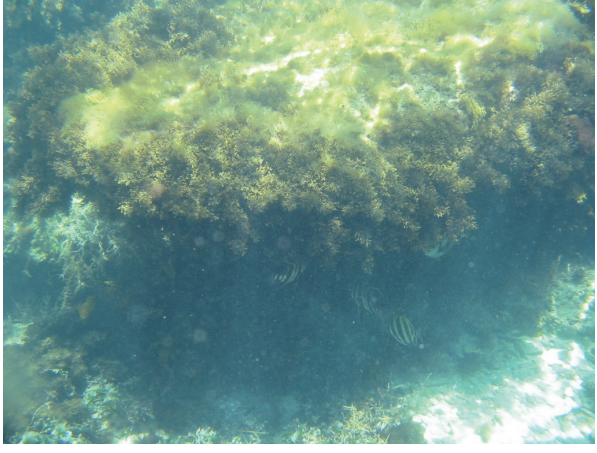

(a)

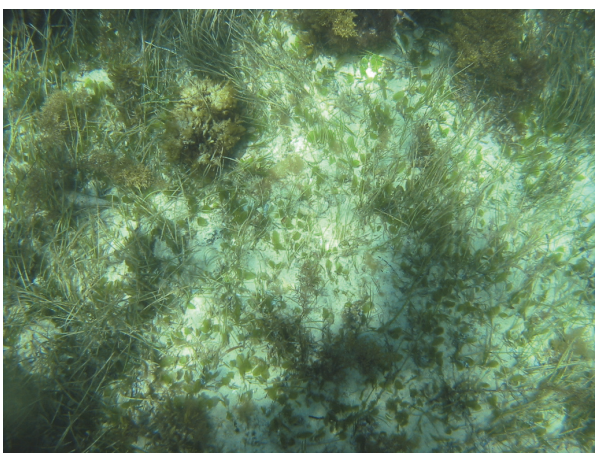

(c)

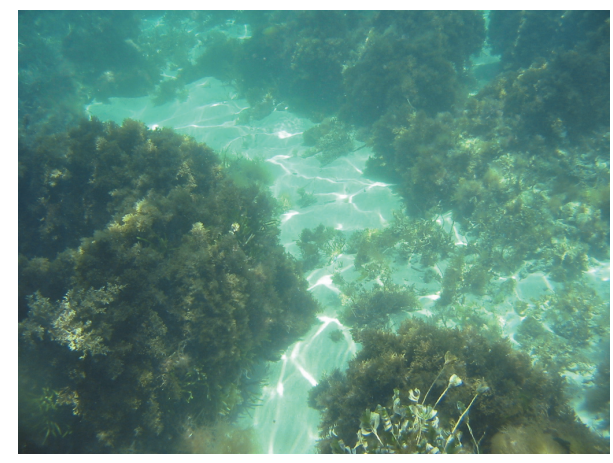

(b)

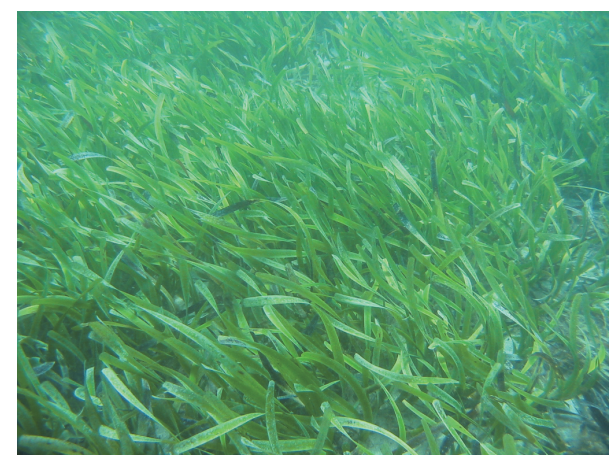

(d)

FIgURE 1: A selection of marine algae and seagrasses along the West Australian coastline: (a) Sargassum species and filamentous algae; (b) Amphibolis antarctica; (c) mixed seagrasses and algae; and (d) seagrass Posidonia australis Hook. f.

active compounds present in seaweeds can act as both metalreducing agents and capping agents during the formation of stable nanoparticles. Moreover, current studies by the authors have also shown that some species of seagrass contain active compounds that can readily synthesize stable metal nanoparticles. This review summarizes the current state of research into the biogenic synthesis of metal and metal oxide nanoparticles using marine algae and seagrasses. The review also discusses factors influencing the synthesis process and potential applications for nanoparticles produced via marine plants.

\section{Toxicology and Biosynthesis of Nanoparticles}

2.1. Toxicology of Nanoparticles. Nanoparticles with their unique size-dependent properties are at the forefront of advanced material engineering applications in several fields. However, recent concerns about the toxicological impact of nanoparticles to human health and the environment have created uneasiness in the wider community. Larger surface areato-volume ratios of nanoparticles mean that more parameters must be considered when compared to conventional bulk scale materials. For example, parameters such as particle size, morphology, composition, concentration, chemical reactivity, dispersion, and aggregation can all directly influence the behavior and interactions between nanoparticles and specific environments. In the case of nanoparticle size, studies have shown that particles around $10 \mathrm{~nm}$ can induce greater human cell death rates when compared to larger particles ranging in size from 50 to $100 \mathrm{~nm}[66,67]$. Furthermore, nanoparticles of the same composition can display behavioral differences when interacting with different environments. These differences can result from slight variations in particle size, morphology, surface reactivity, and surface coatings. Another source of behavioral differences can also result from manufacturing process. For example, conventional chemical and physical manufacturing processes tend to use hazardous chemicals such as surfactants. These surfactants act as sculpturing agents that direct particle growth. While capping agents are generally used to stabilize and prevent nanoparticle aggregation. Toxicity issues arise because it is extremely difficult to remove all chemical contaminants from the surface of nanoparticles [68]. Furthermore, studies have shown that naked nanoparticles do not exist for very long in biological or environmental surroundings. Their high surface energies attract atoms and molecules, which rapidly coat and change surface properties [69]. In a biological setting, biomolecules such as enzymes and proteins rapidly attach to nanoparticles to form surface layering or corona as seen in Figure 2 [70].

The difficulty in determining toxicity arises from how nanoparticles bind and interact with biological materials and living organisms. How these binding and interaction mechanisms change nanoparticle surface properties and their subsequent influence in living organisms are not fully understood [71]. For example, silver (Ag) has been used as an 


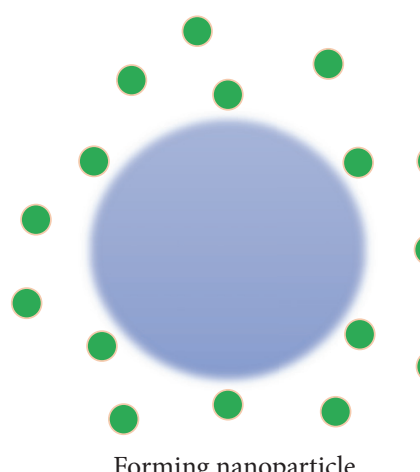

Forming nanoparticle

(a)

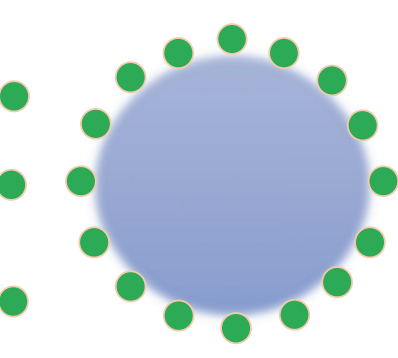

Stabilized nanoparticle coated with capping agent

(b)

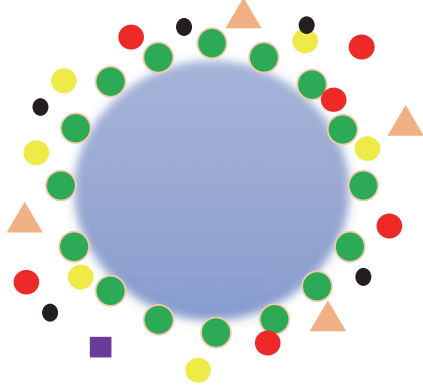

Proteins and enzymes in biological environment weakly attaching to nanoparticle

(c)

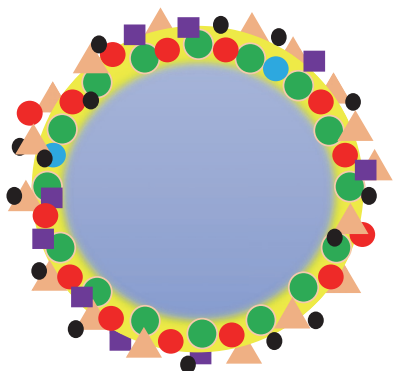

Nanoparticle Corona Equilibrium layer formed with surrounding environment

(d)

FIGURE 2: Biosynthesis and subsequent formation of nanoparticle corona: (a) biosynthesis of naked particle, (b) stabilization of nanoparticle by capping agents in algal extract solution, (c) naked nanoparticle in biological environment, and (d) proteins and enzymes firmly attached to nanoparticle surface to form an equilibrium layer with the surrounding environment.

antimicrobial agent for centuries and the use of Ag nanoparticles in recent years has significantly increased the effectiveness of Ag as a medicinal preparation [72,73]. However, using high concentrations of $\mathrm{Ag}$ nanoparticles can induce toxicity and as a consequence produce a variety of health problems [74]. Furthermore, studies have also shown the release of Ag nanoparticles into the environment can produce significant ecological problems $[66,75]$. Therefore, toxicity results not only from nanoparticle size, morphology, composition, and surface reactivity, but also from the presence of surface contaminants. This added complication makes it necessary to understand the interaction of formation chemicals during synthesis and ultimately the interactions occurring in environment to determine potential toxicity issues $[76,77]$.

To reduce the toxicity concerns, there needs to be greater attention paid to finding alternative clean, nontoxic, and ecofriendly green chemistry based approaches for manufacturing nanoparticles. Importantly, the interactions between a nanoparticle and its surrounding environment is a surface phenomenon [78]. Thus, surface and surface contaminants are actively involved in the nanoparticle/environment interface rather than the nanoparticles material core. Because of the importance of nanoparticle/environmental interactions, the presence of any harmful surface toxic residues will prevent nanoparticles being used in therapeutic applications. Thus, the medical use of nanoparticle-based pharmaceuticals will be ultimately evaluated on their therapeutic benefit against any toxicity risks. Therefore, in an attempt to reduce toxicity risks, recent research has focused on biologically based synthesis techniques. Biosynthesis of nanoparticles via biological entities has the potential to deliver a clean and ecofriendly approach. In particular, biomolecules present in marine algae and seagrasses have the capability to synthesize a wide variety of nanoparticles with very low to no toxicity risks.

2.2. Biosynthesis of Nanoparticles. The biogenic synthesis of nanoparticles via marine algae and seagrasses is considered to be a clean, nontoxic, and ecofriendly green chemistry approach with the potential to deliver a wide variety of particle sizes, morphologies, compositions, and physicochemical properties. The use of natural renewable marine resources like seaweed-derived polysaccharides has been exploited for many years by the food industry $[49,79]$. The cell walls present in seaweeds are composed of polysaccharides. These polysaccharides mainly consist of small sugar units linked via glycosidic bonds, which have hydrophilic surface groups such as carboxyl, hydroxyl, and sulfate groups [80]. Typical polysaccharides found in seaweeds include agar, alginate, carrageenan, fucoidan, and laminarin [81]. Other biomolecules found in the cell walls include proteins and enzymes. The presence of these bioactive materials has attracted considerable interest in recent years and has resulted in the creation of food products, renewable bioenergy, and biomedical applications [82-84].

At present, there is no detailed understanding of the mechanisms behind the formation of nanoparticles by seaweeds and seagrasses. However, studies have revealed that many of the biomolecules present in the cell walls of several seaweeds can act as biocatalysts to assist in the reduction of precursor metal salts to nucleate metal and metal oxide nanoparticles [65, 85-87], while other larger amphiphilic biomolecules act as surfactants, which direct and control nanoparticle growth [88]. The biogenic synthesis of nanoparticles is a relatively straightforward room temperature process as seen in Figure 3 and begins by mixing a metal salt solution with an aqueous solution containing either seaweed or seagrass extract. Reduction starts immediately and a color change in the reaction mixture indicates the formation of nanoparticles. For example, in a recent study by Arockiya et al., gold $(\mathrm{Au})$ nanoparticles were synthesized using brown alga (Stoechospermum marginatum). Nanoparticle formation occurred within $10 \mathrm{~min}$ and was clearly seen by the reaction mixture changing from a pale brown to a ruby red color [38]. Subsequent electron microscopy analysis revealed the nanoparticles ranged in size from 18.7 to $93.7 \mathrm{~nm}$ and were 

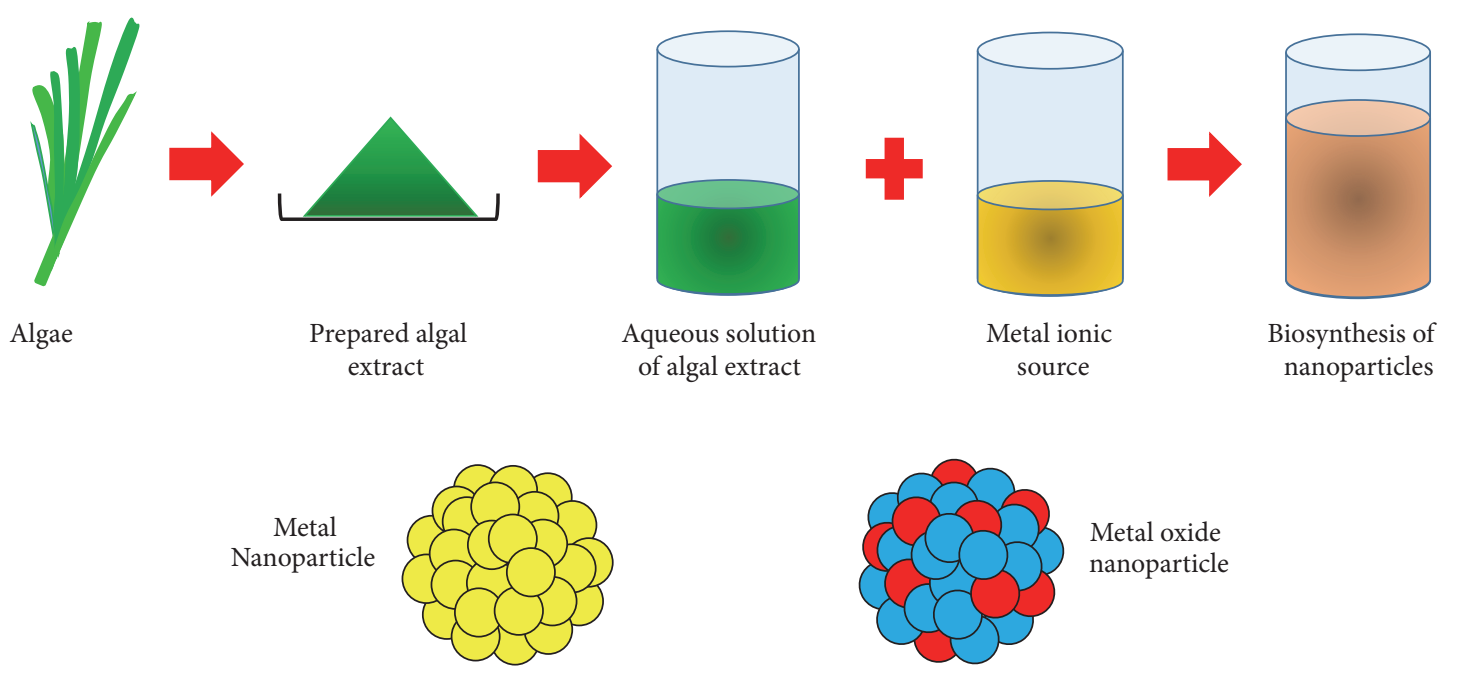

FIGURE 3: Bottom up assembly of atoms via biosynthesis using marine algae and metallic ionic sources to form metal or metal oxide nanoparticles.

predominantly spherical with smaller numbers of hexagonal and triangular platelets.

It is believed that the growth of nanoparticles in solution begins with metal ions being converted from their mono or divalent oxidation states to zero-valent states. This is followed by metal ion reduction and subsequent nucleation [89]. Following initial nucleation, a kinetically controlled process takes place in which smaller neighboring particles attach to low energy faces of the forming crystal to create larger thermodynamically stable nanoparticles. As growth progresses, biomolecules contained within either the seaweed or seagrass extract act as natural surfactants (capping agents) on specific facets of the forming crystal [90]. The adsorption of the capping agents and their subsequent interactions on the crystal facets reduce interfacial energy and lower surface tension [91]. The modified surface's properties of the crystal facet tend to influence the orientation and assembly of subsequent growth [92]. Thus, growth occurs in preferential planes and explains the morphologies seen in biosynthesized nanoparticles. Typical morphologies produced via biosynthesis include cubes, hexagons, pentagons, rods, spheres, triangles, and wires [34, 93].

Biomolecules present in seaweeds and seagrasses also have the ability to influence particle size, morphology, composition, and physicochemical properties of the synthesized nanoparticles. Ultimately, it is the effective control of these properties that defines the quality of the nanoparticles. However, a considerable amount of research is needed to identify and determine the role of specific biomolecules involved in the formation process and the influence of individual biomolecules in dictating nanoparticle growth mechanisms. Currently, experimental parameters such as concentration of seaweed or seagrass extract, metal salt concentration, solution mixture $\mathrm{pH}$, reaction time, and temperature are being investigated by several researchers. Since these parameters have a significant effect on the quality and properties of the synthesized nanoparticles $[31,94]$.

\section{Types of Nanoparticles Produced by Marine Algae and Marine Plants}

At present, only a relatively small amount of the literature reports the use of marine algae and other marine plants for the biosynthesis of nanoparticles, while recent studies have also shown that several forms of marine algae can be used for the bioremediation of toxic metals [85]. The biosynthesis of nanoparticles via marine algae and other marine plants is a new and emerging research field. Several studies have shown these biological entities to have the potential to produce a wide range of metal and metal oxide nanoparticles using ecofriendly methods $[118,119]$. The following sections summarize and discuss currently available literature reports that have investigated a number of marine algae. Table 1 presents a selection of the various metal and metal oxide nanoparticle types biosynthesized using several forms of marine algae.

3.1. Metal Nanoparticles. The biogenic synthesis of metal nanoparticles using marine algae from precursor metal salts is a facile room temperature process. Synthesis begins by mixing a metal salt solution of known concentration with an aqueous solution containing a seaweed extract. During the initial reduction period, there is a color change in the reaction mixture indicating that nanoparticle nucleation has taken place. With the passage of time the small neighboring nucleonic particles in the reaction mixture start agglomerating to form larger and more thermodynamically stable nanoparticles. The aggregation and self-assembly of the nucleonic particles are assisted by biomolecules present in the seaweed extract. During self-assembly, the most energetically favorable and stable particle shapes are formed. Typical shapes formed include cubes, hexagons, pentagons, rods, spheres, triangles, and wires [120]. Studies have also shown that nanoparticle formation is influenced by several experimental factors. These factors include (1) algae concentration; (2) metal salt concentration; (3) reaction time; (4) reaction 
TABLE 1: A selection of metal and metal oxide nanoparticles biosynthesized via marine alga.

\begin{tabular}{|c|c|c|c|c|}
\hline Material & NP & Size $(\mathrm{nm}) \&$ shape & Marine alga & Ref. \\
\hline \multirow{8}{*}{ Metals } & $\mathrm{Ag}$ & 3 to 44 , spherical and cubic & Codium capitatum & {$[95]$} \\
\hline & $\mathrm{Ag}$ & 30, spherical & Spirogyra insignis & {$[96]$} \\
\hline & $\mathrm{Ag}$ & 5 to 35 , spherical & Padina tetrastromatica & [97] \\
\hline & $\mathrm{Au}$ & 8 to 15 , spherical & Sargassum wightii Greville & {$[98]$} \\
\hline & $\mathrm{Au}$ & 6 to 10 , spherical \& triangular & Turbinaria conoides & [99] \\
\hline & $\mathrm{Au}$ & 18.7 to 93.7 , spherical & Stoechospermum marginatum & {$[100]$} \\
\hline & $\mathrm{Pd}$ & 2 to 15 , spherical & Chlorella vulgaris & [101] \\
\hline & $\mathrm{Pd}$ & 4 to 6 , spherical & Laminaria digitata & {$[102]$} \\
\hline \multirow{5}{*}{ Metal oxides } & $\mathrm{Cu}_{2} \mathrm{O}, \mathrm{CuO}$ & 5 to 45 , spherical & Bifurcaria bifurcata & [103] \\
\hline & $\mathrm{Cu} / \mathrm{Cu}_{2} \mathrm{O}$ & 53 , spherical & Kappaphycus alvarezii & {$[104]$} \\
\hline & $\mathrm{Fe}_{3} \mathrm{O}_{4}$ & $18 \pm 4$, cubic & Sargassum muticum & {$[65]$} \\
\hline & $\mathrm{ZnO}$ & 3 to 57 , hexagonal & Sargassum muticum & {$[105]$} \\
\hline & $\mathrm{ZnO}$ & 18 to 50 , hexagonal & Gracilaria gracilis & {$[106]$} \\
\hline
\end{tabular}

solution $\mathrm{pH}$; and (5) temperature. Controlling these factors will determine the quality, size, and shape of the biosynthesized nanoparticles [34]. The vast majority of marine plant studies have examined the biogenic synthesis of $\mathrm{Ag}$ and Au nanoparticles using seaweeds, and the following sections summarize the research results to date.

3.1.1. Silver (Ag) Nanoparticles. Historically, Ag has attracted considerable interest due to its antimicrobial properties [121]. Advances in manufacturing processes have enabled the large scale production of Ag nanoparticles with unique physiochemical and antimicrobial properties. The antimicrobial properties and efficacy of Ag nanoparticles towards a variety of microbial entities have resulted in their incorporation into a wide range of pharmaceuticals and medical protocols [121, 122]. The mechanisms associated with their antimicrobial properties are not fully understood, but the interaction between Ag nanoparticles and microbial cell membranes is believed to cause significant membrane damage and biosorption. The increased cellular uptake of nanometer scale Ag results in significant toxicological damage to cellular DNA $[123,124]$. From another perspective, seaweeds are a valuable source of bioactive materials that include a variety of polysaccharides. Due to the presence of these materials, seaweeds are considered to have medicinal and pharmaceutical properties [49]. Therefore, using seaweeds to biosynthesize Ag nanoparticles has the potential to deliver an additional synergic effect and produce nanoparticles with enhanced medicinal properties.

The biosynthesis of Ag nanoparticles using several species of seaweed has been reported by a small number of researchers in recent years. For example, Rajeshkumar et al. have reported the biosynthesis of Ag nanoparticles using brown seaweed Padina tetrastromatica. Their study revealed that the nanoparticles were spherical in shape, had a mean particle size of $14 \mathrm{~nm}$, and displayed antibacterial activity [107]. Similarly, crystalline Ag nanoparticles were biosynthesized from Codium capitatum to produce spherical and cubic nanoparticles ranging in size from 3 to $44 \mathrm{~nm}$, with a mean particle size of $30 \mathrm{~nm}$ [95]. A comparable result was also reported for green alga Spirogyra insignis, which also produced spherical nanoparticles with a mean particle size of $30 \mathrm{~nm}$ [96], while macroalga Padina tetrastromatica was found to produce crystalline spherical nanoparticles ranging in size from 5 to $35 \mathrm{~nm}$ [97]. Ag nanoparticles synthesized by seaweeds have also been found to have antifungal [86, 108], antibacterial [109-113], and anticancer properties [114]. On another front, Ramkumar Vijayan et al. have used an aqueous solution containing an extract taken from Turbinaria conoides to biosynthesize both $\mathrm{Ag}$ and $\mathrm{Au}$ nanoparticles. Their study also investigated the antibiological film formation activity of the nanoparticles against marine biofilm forming bacteria [115]. Also, studies into antimicrobial agents have found that $\mathrm{AgCl}$ nanoparticles biosynthesized using an aqueous extract containing Sargassum plagiophyllum were effective agents against bacterial pathogens such as Escherichia coli [116].

3.1.2. Gold ( $A u)$ Nanoparticles. Au nanoparticles with their unique size dependent properties have been used in a variety of applications that include catalytic agents, biosensors, pharmaceuticals, imaging, and electronics [125-130]. Because of their unique properties and applications, research has focused on using alternative methods for manufacturing $\mathrm{Au}$ nanoparticles. In recent years biological entities have been examined as potential biofactories. And as a result, the biologically diverse marine environment is starting to attract the interest of more researchers worldwide. Because of this interest, a number of recent articles describing the biosynthesis of $\mathrm{Au}$ nanoparticles by both marine and fresh water alga have appeared in the literature.

A study by Romero-González et al. has shown that dealginated seaweed waste can be used to reduce Au ions in solution to form $\mathrm{Au}$ particles ranging from the nanometer scale range up to around $6 \mu \mathrm{m}$ in size. Their study found the functional groups present in the seaweed were capable of producing stable particles of the various shapes that include irregular, decahedral, and hexagonal rods and tetrahedral platelets [85]. 
In a similar study, Mata et al. were able to demonstrate an ecofriendly process that recovered Au from dilute hydrometallurgical solutions. The process involved the biosorption and bioreduction of Au by brown seaweed (Fucus vesiculosus) and resulted in nanoparticles of various sizes and morphologies being produced [63]. Singaravelu et al. have also reported the biosynthesis of $\mathrm{Au}$ nanoparticles using a marine alga Sargassum wightii Greville. In their study the alga rapidly produced stable nanoparticles ranging in size from 8 to $15 \mathrm{~nm}$ and were spherical in shape [98]. In a similar studies by Luangpipat et al. (Chlorella vulgaris) [131], Rajasulochana et al. (Kappaphycus alvarezii) [132] and Stalin Dhas et al. (Sargassum myriocystum) [88] were able to produce a wide range of stable nanoparticle sizes, while Senapati et al. have reported the biosynthesis of Au nanoparticles using marine alga Tetraselmis kochinensis [133] and Rajeshkumar et al. have also reported using Turbinaria conoides to produce $\mathrm{Au}$ nanoparticles ranging in size from 6 to $10 \mathrm{~nm}$ and shapes that included spherical, pseudospherical, and triangular shapes [99]. In addition, Castro et al. have reported the biosynthesis of Au nanoparticles using green alga Spirogyra insignis and red alga Chondrus crispus [96]. And recently, Arockiya Aarthi Rajathi et al. have reported the biosynthesis of Au nanoparticles using a brown alga Stoechospermum marginatum. Their study revealed the nanoparticles were crystalline and ranged in size from 18.7 to $93.7 \mathrm{~nm}$ and were predominantly spherical in shape with small numbers of hexagonal and triangular platelets. The study also found the hydroxyl groups of the diterpenoids present in the brown seaweed were directly involved in Au reduction. The nanoparticles also displayed significant antibacterial activity against a range of selected bacterial pathogens [100]. Crystalline Au nanoparticles ranging in size from 7 to $11 \mathrm{~nm}$ have also been biosynthesized using brown seaweed (Turbinaria ornate) [134] and by another brown seaweed (Padina pavonica) to produce spherical nanoparticles ranging in size from 30 to $70 \mathrm{~nm}$ [117]. Additionally, studies have shown that two species of freshwater algae [green alga (Prasiola crispa) and red alga (Lemanea fluviatilis)] are capable of biosynthesizing Au nanoparticles $[135,136]$.

Furthermore, current preliminary research by the authors has shown that an aqueous solution containing seagrass rhizome extract can biosynthesize Au nanoparticles at room temperature. The seagrass (Posidonia australis Hook. f.) is a marine flowering plant that has adapted to living in the near shore environment along the southern waters of temperate Australia. Figure 4 presents some preliminary results that indicate that metal ion concentration is an important factor in the biosynthesis process. During biosynthesis the reactive mixture changed color from a light yellow to a dark brown, which indicated the formation of Au nanoparticles. Inspection of Figure 4(b) reveals that the mixture containing $1 \mathrm{~mL}$ of $250 \mathrm{ppm}$ gold chloride has turned the darkest shade of brown compared to other concentrations, thus, indicating the influence of gold chloride concentration during the reaction. Electron microscopy analysis reveals that particle sizes ranged from $30 \mathrm{~nm}$ up $80 \mathrm{~nm}$, with a small number of larger hexagonal plates ( $400 \mathrm{~nm}$ to $1 \mu \mathrm{m}$ ) present in the agglomerate as seen in Figures 4(c) and 4(d). Other shapes present in the images are spherical, cubic, and triangular platelets.

3.1.3. Other Metallic Nanoparticles. At present there are very few reports in the literature describing the use of marine and freshwater algae to produce metal nanoparticles other than Ag and Au. However, Scarano and Morelli have reported using the marine phytoplanktonic alga (Phaeodactylum tricornutum Bohlin) to biosynthesize cadmium sulphide (CdS) nanocrystallites when the alga was immersed in aqueous solutions containing Cd ions [137]. Recently, Eroglu et al. have reported the formation of crystalline spherical palladium (Pd) nanoparticles within green microalgae (Chlorella vulgaris) via photosynthetic reactions when the microalgae was immersed in aqueous solutions containing $\mathrm{Na}_{2}\left[\mathrm{PdCl}_{4}\right]$. The nanoparticles ranged in size from 2 to $15 \mathrm{~nm}$, with a mean diameter of $7 \mathrm{~nm}$ [101]. Moreover, a recent study by Parker et al. revealed that Pd nanoparticles could be synthesized using alginic acid and brown seaweed (Laminaria digitata). The study also reported that the majority of nanoparticles produced ranged in size from 4 to $6 \mathrm{~nm}$ [102].

3.2. Metal Oxide Nanoparticles. Metal oxides are an interesting class of inorganic materials that have been extensively explored and studied due to their wide range of structures and properties. The character of metal oxides is more complex than pure metals, with metal oxide bonding varying from nearly ionic to highly covalent and even metallic in nature. Metal oxides come in a variety of different forms, each possessing unique compositions, morphologies, structures, and physiochemical properties [7, 138]. In particular, metal oxide nanoparticles are of particular interest due to their unique and phenomenal optical, electronic, and magnetic properties [139]. These unique properties give metal oxide nanoparticles significant industrial importance in a variety of applications that include catalytic processes, electronics, sensors, magnetic storage media, and solar energy conversion [140-142]. Current literature describing the biosynthesis of metal oxide nanoparticles via marine algae is very limited and has mainly focused on three metal oxide types, namely, copper oxide, ferric oxide, and zinc oxide.

Abboud et al. have reported the biosynthesis of copper oxide nanoparticles using a brown alga extract (Bifurcaria bifurcata). The facile process produced both cuprous oxide nanoparticles $\left(\mathrm{Cu}_{2} \mathrm{O}\right)$ and cupric oxide nanoparticles $(\mathrm{CuO})$. The majority of the nanoparticles were spherical in shape, with a small percentage being slightly elongated. The nanoparticles ranged in size from $5 \mathrm{~nm}$ to $45 \mathrm{~nm}$ and were found to have a mean particle size of $22.6 \mathrm{~nm}$. Subsequent antibacterial studies using Enterobacter aerogenes and Staphylococcus aureus revealed that the copper oxide nanoparticles had good antibacterial properties against both bacterial species [103]. A recent study by Khanehzaei et al. has also reported the biosynthesis of copper cored copper oxide nanoparticles using red seaweed (Kappaphycus alvarezii) extracts. The seaweed acted as an effective stabilizing agent and produced copper cored-cuprous oxide coated nanoparticles that were spherical in shape with a mean particle size of $53 \mathrm{~nm}$. Their study also found the nanoparticle surfaces were capped by 


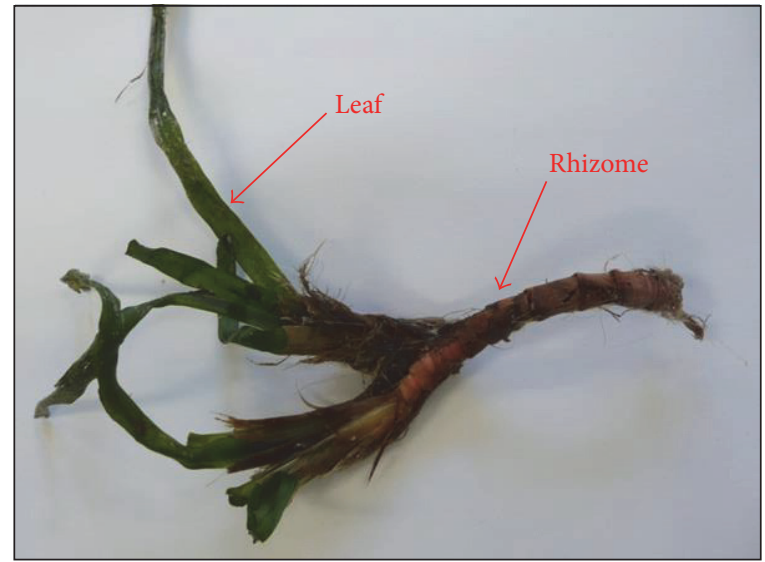

(a)

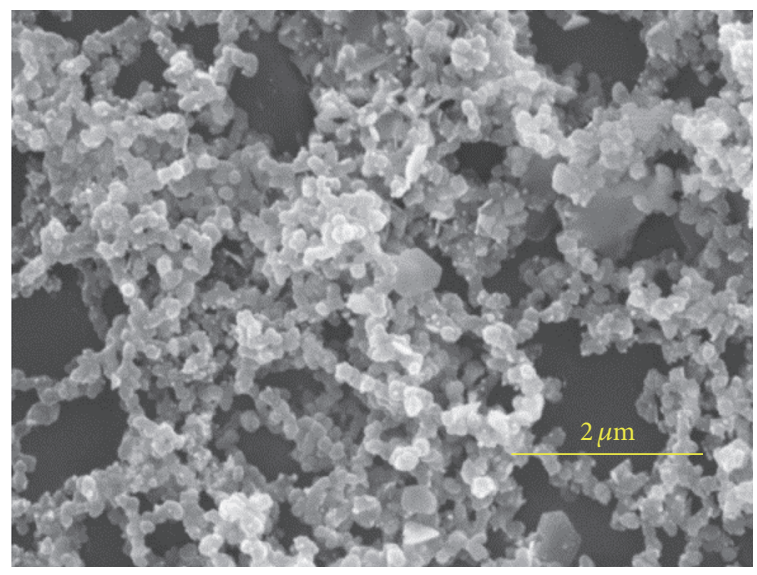

(c)

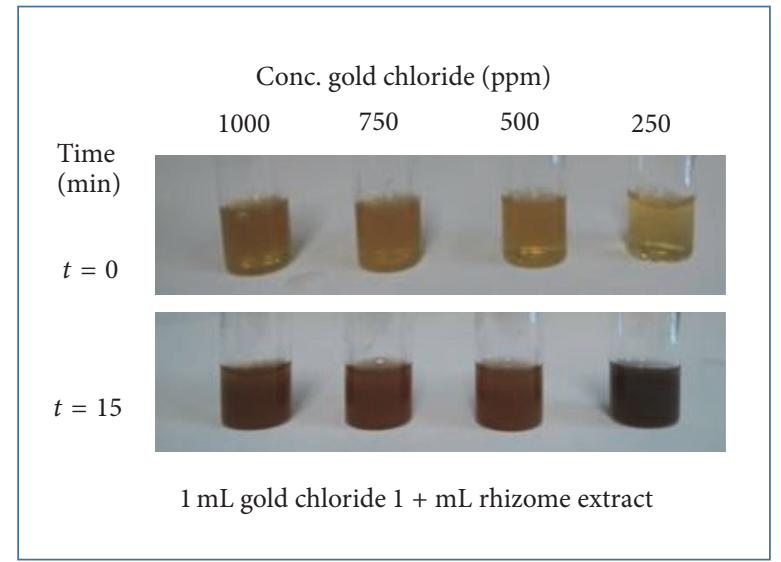

(b)

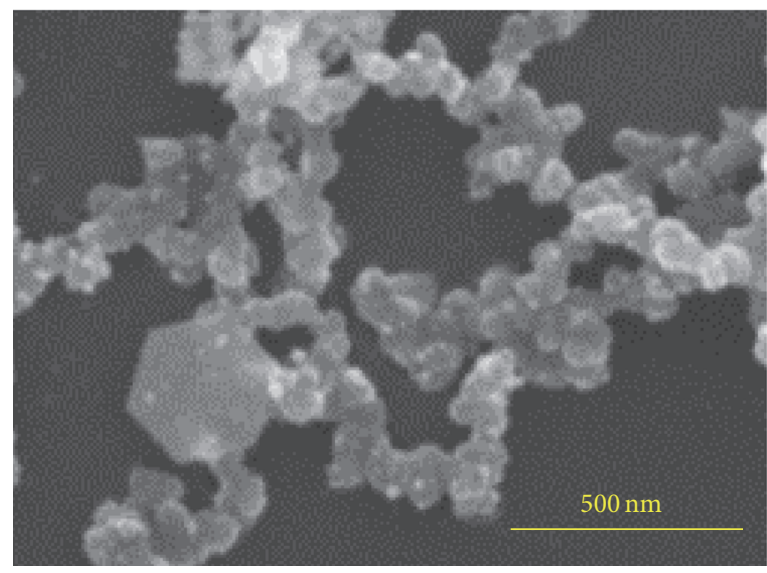

(d)

Figure 4: (a) Marine flowering plant (Posidonia australis Hook. f.), (b) influence of gold chloride concentration (250 to 1000 ppm) in the reactive mixture, (c) electron microscopy image of a representative sample, and (d) an enlarged image of Au nanometer scale hexagonal plates in the sample.

paired oxygen atoms, some hydroxyl and sulphates groups from the water-soluble sulphated polysaccharides derived from the cell walls making up the seaweed [104].

A recent study by Mahdavi et al. found that ferric oxide $\left(\mathrm{Fe}_{3} \mathrm{O}_{4}\right)$ nanoparticles could be synthesized by a one-step green biogenic method using brown seaweed (Sargassum muticum). The aqueous seaweed extract was mixed with an aqueous ferric chloride solution to produce $\mathrm{Fe}_{3} \mathrm{O}_{4}$ nanoparticles. The amino, carboxyl, and hydroxyl functional groups derived from the water-soluble polysaccharide cell walls were found to act as both reducing agent and capping agent. The mean particle size produced was $18 \pm 4 \mathrm{~nm}$, crystalline in nature, and having a cubic morphology [65]. Subsequent in vitro studies by Namvar et al. using the derived $\mathrm{Fe}_{3} \mathrm{O}_{4}$ nanoparticles evaluated their cytotoxicity, cellular responses, and anticancer activity towards human cell lines for leukemia, breast cancer, cervical cancer, and liver cancer. The in vitro studies found the accumulation of $\mathrm{Fe}_{3} \mathrm{O}_{4}$ nanoparticles in treated cells tended to promote cell apoptosis and confirmed their potential use in the treatment of cancer [143].
Current biosynthesis research using seaweeds has also examined protocols for producing zinc oxide $(\mathrm{ZnO})$ nanoparticles. $\mathrm{ZnO}$ nanoparticles have exceptional electrical and optical properties, which makes them suitable for a wide range of applications such as biomedical, photocatalysts and solar cells [144-146]. Recently Nagarajan and Kuppusamy examined three types of seaweed that included green (Caulerpa peltata), red (Hypnea valentiae), and brown (Sargassum myriocystum) for the biosynthesis of $\mathrm{ZnO}$ nanoparticles. After investigating experimental parameters such as metal ion concentration, seaweed extract concentration, temperature, $\mathrm{pH}$, and reaction time, brown seaweed (Sargassum myriocystum) was found to be effective in producing $\mathrm{ZnO}$ nanoparticles [87]. Their study also revealed that the soluble photochemicals present in Sargassum myriocystum such as alginic acid, ascorbic acid, protein, carbohydrates, flavanoids, tannins, mannitols, and lipids acted as both reduction and stabilizing agents. The morphology of the synthesized nanoparticles included spherical, triangular, hexagonal, rod, and rectangular types. The particle sizes ranged from $76 \mathrm{~nm}$ 
TABLE 2: A selection of nanoparticles and their antimicrobial against various pathogens.

\begin{tabular}{|c|c|c|c|c|}
\hline NP & Size $(\mathrm{nm}) \&$ shape & Alga & Antimicrobial activity & Ref. \\
\hline $\mathrm{Ag}$ & 14 , spherical & Padina tetrastromatica & $\begin{array}{l}\text { Pseudomonas sp., Escherichia coli, Bacillus subtilis, Klebsiella } \\
\text { planticola }\end{array}$ & [107] \\
\hline $\mathrm{Ag}$ & $\begin{array}{l}18 \text { to } 44, \\
\text { spherical }\end{array}$ & Gracilaria corticata & Candida albicans, Candida glabrata & {$[86]$} \\
\hline $\mathrm{Ag}$ & $\begin{array}{l}22, \\
\text { spherical }\end{array}$ & Gelidiella acerosa & $\begin{array}{c}\text { Humicola insolens, Fusarium dimerum, Mucor indicus, } \\
\text { Trichoderma reesei }\end{array}$ & {$[108]$} \\
\hline $\mathrm{Ag}$ & $\begin{array}{l}8-27, \\
\text { spherical }\end{array}$ & $\begin{array}{l}\text { Sargassum wightii } \\
\text { Grevilli }\end{array}$ & $\begin{array}{c}\text { Staphylococcus aureus, Bacillis rhizoids, Escherichia coli, } \\
\text { Pseudomonas aeruginosa }\end{array}$ & [109] \\
\hline $\mathrm{Ag}$ & $\begin{array}{l}\text { 20-30, } \\
\text { spherical }\end{array}$ & Urospora sp. & $\begin{array}{c}\text { Staphylococcus aureus, Escherichia coli, Pseudomonas aeruginosa, } \\
\text { Klebsiella pneumonia, Bacillis subtilis }\end{array}$ & [110] \\
\hline $\mathrm{Ag}$ & $\begin{array}{l}20, \\
\text { spherical }\end{array}$ & Ulva lactuca & Bacillus sp., Escherichia coli, Pseudomonas sp. & {$[111]$} \\
\hline $\mathrm{Ag}$ & $\begin{array}{l}\text { 2-32, } \\
\text { spherical }\end{array}$ & $\begin{array}{l}\text { Enteromorpha flexuosa } \\
\text { Wulfen }\end{array}$ & $\begin{array}{c}\text { Bacillus subtilis, Bacillus pumilus, Enterococcus faecalis, } \\
\text { Staphylococcus aureus, Staphylococcus epidermidis, Escherichia coli, } \\
\text { Klebsiella pneumonia, Pseudomonas aeruginosa, Aspergillus niger, } \\
\text { Candida albicans, Saccharomyces cerevisiae }\end{array}$ & {$[112]$} \\
\hline $\mathrm{Ag}$ & $\begin{array}{l}5-22, \\
\text { spherical }\end{array}$ & Sargassum wightii & $\begin{array}{c}\text { Pseudomonas aeruginosa, Vibrio cholera, Klebsiella pneumonia, } \\
\text { Staphylococcus aureus, Escherichia coli, Staphylococcus pneumoniae, } \\
\text { Salmonella typhi }\end{array}$ & {$[113]$} \\
\hline $\mathrm{Ag}$ & $\begin{array}{l}50 \text { to } 100 \\
\text { spherical }\end{array}$ & $\begin{array}{l}\text { Sargassum polycystum } \\
\text { C. Agardh }\end{array}$ & $\begin{array}{c}\text { Pseudomonas aeruginosa, Klebsiella pneumonia, Escherichia coli, } \\
\text { Staphylococcus aureus, MCF breast cancer }\end{array}$ & {$[114]$} \\
\hline $\mathrm{Ag} \& \mathrm{Au}$ & $\begin{array}{l}<60, \\
\text { spherical \& } \\
\text { triangular }\end{array}$ & Turbinaria conoides & $\begin{array}{l}\text { Salmonella sp., Escherichia coli, Serratia liquefaciens, Aeromonas } \\
\text { hydrophila }\end{array}$ & {$[115]$} \\
\hline $\mathrm{AgCl}$ & $\begin{array}{l}\text { 21-48, } \\
\text { spherical }\end{array}$ & $\begin{array}{l}\text { Sargassum } \\
\text { plagiophyllum }\end{array}$ & Escherichia coli & {$[116]$} \\
\hline $\mathrm{Au}$ & $\begin{array}{l}\text { 18.7-93.7, } \\
\text { spherical, } \\
\text { hexagonal, } \\
\text { triangular }\end{array}$ & $\begin{array}{l}\text { Stoechospermum } \\
\text { marginatum (kützing) }\end{array}$ & $\begin{array}{c}\text { Pseudomonas aeruginosa, Klebsiella oxytoca, Enterobacter faecalis, } \\
\text { Klebsiella pneumoniae, Vibrio parahaemolyticus, Vibrio cholerae, } \\
\text { Escherichia coli, Salmonella typhi, Salmonella paratyphi, Proteus } \\
\text { vulgaris }\end{array}$ & [100] \\
\hline $\mathrm{Au}$ & $\begin{array}{l}30-70 \\
\text { spherical }\end{array}$ & Padina pavonica & Bacillus subtilis, Escherichia coli & {$[117]$} \\
\hline $\begin{array}{l}\mathrm{Cu}_{2} \mathrm{O} \\
\mathrm{CuO}\end{array}$ & $\begin{array}{l}5-45 \\
\text { spherical }\end{array}$ & Bifurcaria bifurcata & Enterobacter aerogenes, Staphylococcus aureus & [103] \\
\hline $\mathrm{ZnO}$ & $\begin{array}{l}96-110, \\
\text { spherical, } \\
\text { rectangular, } \\
\text { triangular }\end{array}$ & Sargassum myriocystum & $\begin{array}{c}\text { Staphylococcus mutans, Micrococcus luteus, Vibrio cholera, } \\
\text { Klebsiella pneumonia, Neisseria gonorrhoeae }\end{array}$ & {$[87]$} \\
\hline
\end{tabular}

up $186 \mathrm{~nm}$. Furthermore, both particle size and morphology were found to be strongly influenced by the experimental parameters. For example, both particle size and morphology were influenced by temperature, while biosynthesis carried out at $\mathrm{pH} 8$ tended to predominantly produce nanoparticles with a mean size of $36 \mathrm{~nm}$.

A similar study by Azizi et al. using a brown seaweed (Sargassum muticum) discovered that bioactive materials such as amino, sulfate, carboxyl, and hydroxyl groups all played a significant role during the biosynthesis process. The resulting $\mathrm{ZnO}$ nanoparticles were found to have a hexagonal crystal morphology and ranged in size from 3 to $57 \mathrm{~nm}$ [105]. Subsequent in vitro cytotoxicity studies using murine cancer cell lines indicated various levels of cytotoxicity over a $72 \mathrm{~h}$ trial period. However, suppression of cell growth and proliferation in the WEHI-3 cell line suggest that the $\mathrm{ZnO}$ nanoparticles could offer an alternative chemotherapeutic treatment in the future [147].

An alternative $\mathrm{ZnO}$ biosynthesis method has also been examined by Francavilla et al. In their procedure agar extracted from the red seaweed (Gracilaria gracilis) is used as a sacrificial template material during a reactive milling process. During milling the zinc precursor $\mathrm{Zn}\left(\mathrm{NO}_{3}\right)_{2}$ was transformed into a highly crystalline hexagonal wurtzite structure, with nanoparticles ranging in size from 18 to $50 \mathrm{~nm}$. After calcination at $600^{\circ} \mathrm{C}$, the porous $\mathrm{ZnO}$ nanoparticles were found to have excellent photocatalytic properties and could be used to degrade aqueous solutions of phenol [106].

\section{Applications and Future Perspectives}

Nanoparticles have attracted considerable interest in recent years and accordingly have been extensively reported in the 
literature. The unique size and shape dependent physicochemical surface properties make nanoparticles more interactive and reactive to certain chemical species compared to their bulk scale counterparts. The novel properties have been extensively investigated and evaluated for a wide range of applications in a number of fields. Among noble metals, Ag nanoparticles are used as a broad spectrum antimicrobial agent in the biomedical field. Table 2 presents a summary of reported algae synthesized Ag nanoparticles and their respective antimicrobial activity against various pathogens. Inspection of Table 2 also reveals that Au nanoparticles display antimicrobial properties towards a variety of pathogens. To date, the biosynthesis of $\mathrm{Ag}$ and $\mathrm{Au}$ nanoparticles by marine algae has focused on their antimicrobial properties against several pathogens. Therefore, future studies are needed to confirm that the physiochemical properties of $\mathrm{Ag}$ and $\mathrm{Au}$ nanoparticles synthesized by marine algae have similar properties to those produce by more conventional manufacturing processes and can be used in other applications.

This is of particular importance since conventionally manufactured Au nanoparticles have been used in a variety of biomedical applications such as carriers for anticancer drugs $[16,19,129,148]$, biosensors [6], and targets in tumors for thermal treatment therapies $[149,150] . \mathrm{Fe}_{3} \mathrm{O}_{4}$ nanoparticles are another interesting type of nanometer scale material with unique super paramagnetic properties. The magnetic properties of the magnetite nanoparticles make them ideal candidates for magnetic resonance imaging (MRI) and targeted drug delivery applications $[16,151]$. However, very few studies have reported using marine algae to produce $\mathrm{Fe}_{3} \mathrm{O}_{4}$ nanoparticles as seen in Table 1. Similarly, very few studies have been reported in the literature describing the biosynthesis of zinc oxide and copper oxides via marine algae. Oxides are of particular interest, since copper oxide nanoparticles have antibacterial properties [103] and zinc oxide nanoparticles display both therapeutic [147] and photocatalytic properties [106]. Overall, the biogenic synthesis of metal and metal oxide nanoparticles using marine algae and marine plants is a largely unknown area of research with relatively few articles being reported in the literature. This review has summarized the currently available articles reported in the literature. However, the relatively small number of articles appearing in the literature indicates that further research is needed to fully explore the prospective properties of marine algae and marine plants for the biosynthesis of metal and metal oxide nanoparticles. In addition, further research is needed to fully explore the potential use of these metal and metal oxide nanoparticles in new pharmaceuticals and medical treatments.

\section{Conclusions}

The biogenic synthesis of metal and metal oxide nanoparticles has attracted considerable interest in recent years. This interest springs from the unique nanoparticle properties, which makes them highly desirable for a wide range of pharmaceutical and biomedical applications. The biogenic synthesis of nanoparticles by marine algae and marine plants has the potential to deliver a facile, green, and ecofriendly approach. This green chemistry based approach has the potential to deliver an alternative approach to conventional manufacturing processes that tend to use toxic chemicals and solvents. The studies discussed in the present review have reported that polysaccharides, proteins, and other bioactive chemicals found in the cell membranes of marine alga can act as both reducing and capping agents. However, only a relatively small number of marine algae and marine plants have been studied to date and the research area remains largely unknown. Thus, there are unique opportunities for exploration and developing new green chemistry based biogenic processes for the production of metal and metal oxide nanoparticles. Hopefully, this review will inspire much needed research in this relatively new and unexplored field.

\section{Competing Interests}

The authors declare that they have no competing interests.

\section{Acknowledgments}

Derek Fawcett would like to thank Horticulture Innovation Australia for their research support through Project Al14003.

\section{References}

[1] P. T. Anastas and J. C. Warner, Green Chemistry: Theory and Practice, Oxford University Press, Oxford, UK, 2000.

[2] D. S. Goodsell, Bionanotechnology: Lessons from Nature, John Wiley \& Sons, Hoboken, NJ, USA, 2004.

[3] K. Bogunia-Kubik and M. Sugisaka, "From molecular biology to nanotechnology and nanomedicine," BioSystems, vol. 65, no. 2-3, pp. 123-138, 2002.

[4] M.-C. Daniel and D. Astruc, "Gold nanoparticles: assembly, supramolecular chemistry, quantum-size-related properties, and applications toward biology, catalysis, and nanotechnology," Chemical Reviews, vol. 104, no. 1, pp. 293-346, 2004.

[5] G. A. Mansoori, T. F. George, L. Assoufid, and G. Zhang, Molecular building blocks for nanotechnology, vol. 109 of Topics in Applied Physics, Springer, New York, NY, USA, 2007.

[6] D. A. Jefferson, "The surface activity of ultrafine particles," Philosophical Transactions of the Royal Society A: Mathematical, Physical and Engineering Sciences, vol. 358, no. 1775, pp. 26832692, 2000.

[7] U. Kreibig and M. Vollmer, Optical Properties of Metal Clusters, Springer, Berlin, Germany, 1995.

[8] M. M. Miller, G. A. Prinz, S.-F. Cheng, and S. Bounnak, "Detection of a micron-sized magnetic sphere using a ringshaped anisotropic magnetoresistance-based sensor: a model for a magnetoresistance-based biosensor," Applied Physics Letters, vol. 81, no. 12, pp. 2211-2213, 2002.

[9] O. Akhavan and E. Ghaderi, " $\mathrm{Cu}$ and $\mathrm{CuO}$ nanoparticles immobilized by silica thin films as antibacterial materials and photocatalysts," Surface and Coatings Technology, vol. 205, no. 1, pp. 219-223, 2010.

[10] J. Zhang, Y. Wang, H. Ji et al., "Magnetic nanocomposite catalysts with high activity and selectivity for selective hydrogenation of ortho-chloronitrobenzene," Journal of Catalysis, vol. 229, no. 1, pp. 114-118, 2005. 
[11] H. Fu, X. Yang, X. Jiang, and A. Yu, "Bimetallic Ag-Au nanowires: synthesis, growth mechanism, and catalytic properties," Langmuir, vol. 29, no. 23, pp. 7134-7142, 2013.

[12] E. C. Njagi, H. Huang, L. Stafford et al., "Biosynthesis of iron and silver nanoparticles at room temperature using aqueous sorghum bran extracts," Langmuir, vol. 27, no. 1, pp. 264-271, 2011.

[13] M. Mahdavi, M. B. Ahmad, M. J. Haron, Y. Gharayebi, K. Shameli, and B. Nadi, "Fabrication and Characterization of $\mathrm{SiO} 2 /(3-$ Aminopropyl)triethoxysilane-Coated Magnetite Nanoparticles for Lead(II) Removal from Aqueous Solution," Journal of Inorganic and Organometallic Polymers and Materials, vol. 23, no. 3, pp. 599-607, 2013.

[14] J. Guo, R. Wang, W. W. Tjiu, J. Pan, and T. Liu, "Synthesis of Fe nanoparticles@graphene composites for environmental applications," Journal of Hazardous Materials, vol. 225-226, pp. 63-73, 2012.

[15] W. C. W. Chan and S. Nie, "Quantum dot bioconjugates for ultrasensitive nonisotopic detection," Science, vol. 281, no. 5385, pp. 2016-2018, 1998.

[16] X. Liu, Q. Dai, L. Austin et al., "A one-step homogeneous immunoassay for cancer biomarker detection using gold nanoparticle probes coupled with dynamic light scattering," Journal of the American Chemical Society, vol. 130, no. 9, pp. 2780-2782, 2008.

[17] Q. A. Pankhurst, J. Connolly, S. K. Jones, and J. Dobson, "Applications of magnetic nanoparticles in biomedicine," Journal of Physics D: Applied Physics, vol. 36, no. 13, pp. R167-R181, 2003.

[18] A. K. Gupta and M. Gupta, "Synthesis and surface engineering of iron oxide nanoparticles for biomedical applications," Biomaterials, vol. 26, no. 18, pp. 3995-4021, 2005.

[19] X. Huang, P. K. Jain, I. H. El-Sayed, and M. A. El-Sayed, "Determination of the minimum temperature required for selective photothermal destruction of cancer cells with the use of immunotargeted gold nanoparticles," Photochemistry and Photobiology, vol. 82, no. 2, pp. 412-417, 2006.

[20] M.-T. Hsiao, S.-F. Chen, D.-B. Shieh, and C.-S. Yeh, "Onepot synthesis of hollow Au3Cul spherical-like and biomineral botallackite $\mathrm{Cu} 2(\mathrm{OH}) 3 \mathrm{Cl}$ flowerlike architectures exhibiting antimicrobial activity," Journal of Physical Chemistry B, vol. 110, no. 1, pp. 205-210, 2006.

[21] I. Sondi and B. Salopek-Sondi, "Silver nanoparticles as antimicrobial agent: a case study on E. coli as a model for Gramnegative bacteria," Journal of Colloid and Interface Science, vol. 275, no. 1, pp. 177-182, 2004.

[22] B. D. Chithrani, A. A. Ghazani, and W. C. W. Chan, "Determining the size and shape dependence of gold nanoparticle uptake into mammalian cells," Nano Letters, vol. 6, no. 4, pp. 662-668, 2006.

[23] G. F. Paciotti, L. Myer, D. Weinreich et al., "Colloidal gold: a novel nanoparticle vector for tumor directed drug delivery," Drug Delivery: Journal of Delivery and Targeting of Therapeutic Agents, vol. 11, no. 3, pp. 169-183, 2004.

[24] Z.-Q. Wen, G. Li, and D. Ren, "Detection of trace melamine in raw materials used for protein pharmaceutical manufacturing using surface-enhanced Raman spectroscopy (SERS) with gold nanoparticles," Applied Spectroscopy, vol. 65, no. 5, pp. 514-521, 2011.

[25] H. S. Naiwa, Handbook of Nanostructural Material and Nanotechnology, Academic Press, New York, NY, USA, 2000.
[26] R. Nielson, B. Kaehr, and J. B. Shear, "Microreplication and design of biological architectures using dynamic-mask multiphoton lithography," Small, vol. 5, no. 1, pp. 120-125, 2009.

[27] A. J. Birnbaum and A. Pique, "Laser induced extra-planar propulsion for three-dimensional microfabrication," Applied Physics Letters, vol. 98, no. 13, pp. 134101-134106, 2011.

[28] G. E. J. Poinern, P. Chapman, X. Le, and D. Fawcett, "Green biosynthesis of gold nanometre scale plates using the leaf extracts from an indigenous Australian plant Eucalyptus macrocarpa," Gold Bulletin, vol. 46, no. 3, pp. 165-173, 2013.

[29] F. Cheng, J. W. Betts, S. M. Kelly, J. Schaller, and T. Heinze, "Synthesis and antibacterial effects of aqueous colloidal solutions of silver nanoparticles using aminocellulose as a combined reducing and capping reagent," Green Chemistry, vol. 15, no. 4, pp. 989-998, 2013.

[30] M. A. Albrecht, C. W. Evans, and C. L. Raston, "Green chemistry and the health implications of nanoparticles," Green Chemistry, vol. 8, no. 5, pp. 417-432, 2006.

[31] J. Ai, E. Biazar, M. Jafarpour et al., "Nanotoxicology and nanoparticle safety in biomedical designs," International Journal of Nanomedicine, vol. 6, pp. 1117-1127, 2011.

[32] H. Duan, D. Wang, and Y. Li, "Green chemistry for nanoparticle synthesis," Chemical Society Reviews, vol. 44, no. 16, pp. 57785792, 2015.

[33] N. Kulkarni and U. Muddapur, "Biosynthesis of metal nanoparticles: a review," Journal of Nanotechnology, vol. 2014, Article ID 510246, 8 pages, 2014.

[34] M. Shah, D. Fawcett, S. Sharma, S. K. Tripathy, and G. E. J. Poinern, "Green synthesis of metallic nanoparticles via biological entities," Materials, vol. 8, no. 11, pp. 7278-7308, 2015.

[35] A. Ahmad, S. Senapati, M. I. Khan, R. Kumar, and M. Sastry, "Extracellular biosynthesis of monodisperse gold nanoparticles by a novel extremophilic actinomycete, Thermomonospora sp.", Langmuir, vol. 19, no. 8, pp. 3550-3553, 2003.

[36] M. Lengke and G. Southam, "Bioaccumulation of gold by sulfate-reducing bacteria cultured in the presence of gold(I)thiosulfate complex," Geochimica et Cosmochimica Acta, vol. 70, no. 14, pp. 3646-3661, 2006.

[37] A. Ahmad, S. Senapati, M. I. Khan, R. Kumar, and M. Sastry, "Extra-/intracellular biosynthesis of gold nanoparticles by an alkalotolerant fungus, Trichothecium sp," Journal of Biomedical Nanotechnology, vol. 1, no. 1, pp. 47-53, 2005.

[38] F. Arockiya Aarthi Rajathi, C. Parthiban, V. Ganesh Kumar, and P. Anantharaman, "Biosynthesis of antibacterial gold nanoparticles using brown alga, Stoechospermum marginatum (kützing)," Spectrochimica Acta-Part A: Molecular and Biomolecular Spectroscopy, vol. 99, pp. 166-173, 2012.

[39] D. Philip, "Green synthesis of gold and silver nanoparticles using Hibiscus rosa sinensis," Physica E: Low-Dimensional Systems and Nanostructures, vol. 42, no. 5, pp. 1417-1424, 2010.

[40] S.-W. Lee, C. Mao, C. E. Flynn, and A. M. Belcher, "Ordering of quantum dots using genetically engineered viruses," Science, vol. 296, no. 5569, pp. 892-895, 2002.

[41] M. Kowshik, S. Ashtaputre, S. Kharrazi et al., "Extracellular synthesis of silver nanoparticles by a silver-tolerant yeast strain MKY3," Nanotechnology, vol. 14, no. 1, pp. 95-100, 2003.

[42] P. Mohanpuria, N. K. Rana, and S. K. Yadav, "Biosynthesis of nanoparticles: technological concepts and future applications," Journal of Nanoparticle Research, vol. 10, no. 3, pp. 507-517, 2008.

[43] S. Baker, B. P. Harini, D. Rakshith, and S. Satish, "Marine microbes: invisible nanofactories," Journal of Pharmacy Research, vol. 6, no. 3, pp. 383-388, 2013. 
[44] S. Iravani, "Green synthesis of metal nanoparticles using plants," Green Chemistry, vol. 13, no. 10, pp. 2638-2650, 2011.

[45] A. A. El Gamal, "Biological importance of marine algae," Saudi Pharmaceutical Journal, vol. 18, no. 1, pp. 1-25, 2010.

[46] H. M. El-Rafie, M. H. El-Rafie, and M. K. Zahran, "Green synthesis of silver nanoparticles using polysaccharides extracted from marine macro algae," Carbohydrate Polymers, vol. 96, no. 2, pp. 403-410, 2013.

[47] R. R. Kannan, R. Arumugam, D. Ramya, K. Manivannan, and P. Anantharaman, "Green synthesis of silver nanoparticles using marine macroalga Chaetomorpha linum," Applied Nanoscience, vol. 3, no. 3, pp. 229-233, 2013.

[48] S. K. Kim, Handbook of Marine Macroalgae: Biotechnology and Applied Phycology, John Wiley \& Sons, Chichester, UK, 2011.

[49] A. J. Smit, "Medicinal and pharmaceutical uses of seaweed natural products: a review," Journal of Applied Phycology, vol. 16, no. 4, pp. 245-262, 2004.

[50] L. Liu, M. Heinrich, S. Myers, and S. A. Dworjanyn, "Towards a better understanding of medicinal uses of the brown seaweed Sargassum in Traditional Chinese Medicine: a phytochemical and pharmacological review," Journal of Ethnopharmacology, vol. 142, no. 3, pp. 591-619, 2012.

[51] S. Mohamed, S. N. Hashim, and H. A. Rahman, "Seaweeds: a sustainable functional food for complementary and alternative therapy," Trends in Food Science and Technology, vol. 23, no. 2, pp. 83-96, 2012.

[52] P. Sethi, "Biochemical profile of stoechospermun marginatum," International Journal of Current Pharmaceutical Research, vol. 3, no. 4, pp. 102-104, 2011.

[53] S. Chanda, R. Dave, M. Kaneria, and K. Nagani, "Seaweeds: a novel, untapped source of drugs from sea to combat infectious diseases," in Current Research, Technology and Education Topics in Applied Microbiology and Microbial Biotechnology, A. Mendez-valas, Ed., pp. 473-480, Formatex Research Center, Badazoj, Spain, 2010.

[54] K. Miyashita, "The carotenoid fucoxanthin from brown seaweed affects obesity," Lipid Technology, vol. 21, no. 8-9, pp. 186190, 2009.

[55] A. W. Zuercher, R. Fritsché, B. Corthésy, and A. Mercenier, "Food products and allergy development, prevention and treatment," Current Opinion in Biotechnology, vol. 17, no. 2, pp. 198203, 2006.

[56] K. Wada, K. Nakamura, Y. Tamai et al., "Seaweed intake and blood pressure levels in healthy pre-school Japanese children," Nutrition Journal, vol. 10, article 83, 2011.

[57] M. N. A. Khan, J. S. Choi, M. C. Lee et al., "Anti-inflammatory activities of methanol extracts from various seaweed species," Journal of Environmental Biology, vol. 29, no. 4, pp. 465-469, 2008.

[58] T. Nishino, A. Fukuda, T. Nagumo, M. Fujihara, and E. Kaji, "Inhibition of the generation of thrombin and factor Xa by a fucoidan from the brown seaweed Ecklonia kurome," Thrombosis Research, vol. 96, no. 1, pp. 37-49, 1999.

[59] F. Namvar, S. Mohamed, S. G. Fard et al., "Polyphenol-rich seaweed (Eucheuma cottonii) extract suppresses breast tumour via hormone modulation and apoptosis induction," Food Chemistry, vol. 130, no. 2, pp. 376-382, 2012.

[60] S. Ananthi, H. R. B. Raghavendran, A. G. Sunil, V. Gayathri, G. Ramakrishnan, and H. R. Vasanthi, "In vitro antioxidant and in vivo anti-inflammatory potential of crude polysaccharide from Turbinaria ornata (Marine Brown Alga)," Food and Chemical Toxicology, vol. 48, no. 1, pp. 187-192, 2010.
[61] K. S. Burdin and K. T. Bird, "Heavy metal accumulation by carrageenan and agar producing algae," Botanica Marina, vol. 37, no. 5, pp. 467-470, 1994.

[62] B. A. P. Da Gama, R. C. Pereira, A. G. V. Carvalho, and R. Coutinho, "The effects of seaweed secondary metabolites on biofouling," Biofouling, vol. 18, no. 1, pp. 13-20, 2002.

[63] Y. N. Mata, E. Torres, M. L. Blázquez, A. Ballester, F. González, and J. A. Muñoz, "Gold(III) biosorption and bioreduction with the brown alga Fucus vesiculosus," Journal of Hazardous Materials, vol. 166, no. 2-3, pp. 612-618, 2009.

[64] S. Bharathi Raja, J. Suriya, V. Sekar, and R. Rajasekaran, "Biomimetic of silver nanoparticles by Ulva lactuca seaweed and evaluation of its antibacterial activity," International Journal of Pharmacy and Pharmaceutical Sciences, vol. 4, no. 3, pp. 139143, 2012.

[65] M. Mahdavi, F. Namvar, M. B. Ahmad, and R. Mohamad, "Green biosynthesis and characterization of magnetic iron oxide (Fe3O4) nanoparticles using seaweed (Sargassum muticum) aqueous extract," Molecules, vol. 18, no. 5, pp. 5954-5964, 2013.

[66] D. J. Gorth, D. M. Rand, and T. J. Webster, "Silver nanoparticle toxicity in Drosophila: size does matter," International Journal of Nanomedicine, vol. 6, pp. 343-350, 2011.

[67] C. Carlson, S. M. Hussein, A. M. Schrand et al., "Unique cellular interaction of silver nanoparticles: size-dependent generation of reactive oxygen species," The Journal of Physical Chemistry B, vol. 112, no. 43, pp. 13608-13619, 2008.

[68] A. Gautam and F. C. J. M. Van Veggel, "Synthesis of nanoparticles, their biocompatibility, and toxicity behavior for biomedical applications," Journal of Materials Chemistry B, vol. 1, no. 39, pp. 5186-5200, 2013

[69] T. Cedervall, I. Lynch, S. Lindman et al., "Understanding the nanoparticle-protein corona using methods to quantify exchange rates and affinities of proteins for nanoparticles," Proceedings of the National Academy of Sciences of the United States of America, vol. 104, no. 7, pp. 2050-2055, 2007.

[70] B. Nowack, "The behavior and effects of nanoparticles in the environment," Environmental Pollution, vol. 157, no. 4, pp. 1063 1064,2009

[71] A. Elsaesser and C. V. Howard, “Toxicology of nanoparticles," Advanced Drug Delivery Reviews, vol. 64, no. 2, pp. 129-137, 2012.

[72] K. K. Y. Wong and X. Liu, "Silver nanoparticles—the real 'silver bullet' in clinical medicine?" MedChem Comm, vol. 1, no. 2, pp. 125-131, 2010.

[73] S. A. Cox, L. Cullingworth, and H. Rode, "Treatment of paediatric burns with a nanocrystalline silver dressing compared with standard wound care in a burns unit: a cost analysis," South African Medical Journal, vol. 101, no. 10, pp. 728-731, 2011.

[74] S. Prabhu and E. Poulose, "Silver nanoparticles: mechanism of antimicrobial action, synthesis, medical applications, and toxicity effects," International Nano Letters, vol. 2, article 32, pp. 1-10, 2012.

[75] O. Choi, K. K. Deng, N.-J. Kim, L. Ross Jr., R. Y. Surampalli, and $\mathrm{Z}$. Hu, "The inhibitory effects of silver nanoparticles, silver ions, and silver chloride colloids on microbial growth," Water Research, vol. 42, no. 12, pp. 3066-3074, 2008.

[76] R. D. Handy, F. Von Der Kammer, J. R. Lead, M. Hassellöv, R. Owen, and M. Crane, "The ecotoxicology and chemistry of manufactured nanoparticles," Ecotoxicology, vol. 17, no. 4, pp. 287-314, 2008 . 
[77] A. E. Nel, L. Mädler, D. Velegol et al., "Understanding biophysicochemical interactions at the nano-bio interface," Nature Materials, vol. 8, no. 7, pp. 543-557, 2009.

[78] I. Lynch, T. Cedervall, M. Lundqvist, C. Cabaleiro-Lago, S. Linse, and K. A. Dawson, "The nanoparticle-protein complex as a biological entity; a complex fluids and surface science challenge for the 21st century," Advances in Colloid and Interface Science, vol. 134-135, pp. 167-174, 2007.

[79] D. Renn, "Biotechnology and the red seaweed polysaccharide industry: status, needs and prospects," Trends in Biotechnology, vol. 15, no. 1, pp. 9-14, 1997.

[80] J. Venkatesan, S. Anil, S.-K. Kim, and M. S. Shim, "Seaweed polysaccharide-based nanoparticles: preparation and applications for drug delivery," Polymers, vol. 8, no. 2, article 30, pp. $1-25,2016$.

[81] F. C. N. Barros, D. C. da Silva, V. G. Sombra et al., "Structural characterization of polysaccharide obtained from red seaweed Gracilaria caudata (J Agardh)," Carbohydrate Polymers, vol. 92, no. 1, pp. 598-603, 2013.

[82] M. Panchanathan and K. Se-Kwon, "Introduction to marine bioenergy," in Marine Bioenergy, pp. 3-12, CRC Press, Boca Raton, Fla, USA, 2015.

[83] S. Ermakova, M. Kusaykin, A. Trincone, and Z. Tatiana, "Are multifunctional marine polysaccharides a myth or reality?" Frontiers in Chemistry, vol. 3, article 39, 2015.

[84] J. Venkatesan, I. Bhatnagar, P. Manivasagan, K.-H. Kang, and S.-K. Kim, "Alginate composites for bone tissue engineering: a review," International Journal of Biological Macromolecules, vol. 72, pp. 269-281, 2015.

[85] M. E. Romero-González, C. J. Williams, P. H. E. Gardiner, S. J. Gurman, and S. Habesh, "Spectroscopic studies of the biosorption of gold(III) by dealginated seaweed waste," Environmental Science and Technology, vol. 37, no. 18, pp. 4163-4169, 2003.

[86] P. Kumar, S. Senthamil Selvi, and M. Govindaraju, "Seaweedmediated biosynthesis of silver nanoparticles using Gracilaria corticata for its antifungal activity against Candida spp.," Applied Nanoscience, vol. 3, no. 6, pp. 495-500, 2013.

[87] S. Nagarajan and K. A. Kuppusamy, "Extracellular synthesis of zinc oxide nanoparticle using seaweeds of Gulf of Mannar, India," Journal of Nanobiotechnology, vol. 11, article 39, 2013.

[88] T. Stalin Dhas, V. Ganesh Kumar, L. S. Abraham, V. Karthick, and K. Govindaraju, "Sargassum myriocystum mediated biosynthesis of gold nanoparticles," Spectrochimica Acta Part A: Molecular and Biomolecular Spectroscopy, vol. 99, pp. 97-101, 2012.

[89] P. Malik, R. Shankar, V. Malik, N. Sharma, and T. K. Mukherjee, "Green chemistry based benign routes for nanoparticle synthesis," Journal of Nanoparticles, vol. 2014, Article ID 302429, 14 pages, 2014.

[90] C. L. Bianchi, S. Ardizzone, and G. Cappelletti, "Nanocrystalline oxides: surfactants-assisted growth," in Dekker Encyclopedia of Nanoscience and Nanotechnology, pp. 1-10, 2006.

[91] Y. Xia, P. Yang, Y. Sun et al., "One-dimensional nanostructures: synthesis, characterization, and applications," Advanced Materials, vol. 15, no. 5, pp. 353-389, 2003.

[92] C.-Y. Chiu, L. Ruan, and Y. Huang, "Biomolecular specificity controlled nanomaterial synthesis," Chemical Society Reviews, vol. 42, no. 7, pp. 2512-2527, 2013.

[93] M. S. Akhtar, J. Panwar, and Y.-S. Yun, "Biogenic synthesis of metallic nanoparticles by plant extracts," ACS Sustainable Chemistry and Engineering, vol. 1, no. 6, pp. 591-602, 2013.
[94] A. K. Mittal, Y. Chisti, and U. C. Banerjee, "Synthesis of metallic nanoparticles using plant extracts," Biotechnology Advances, vol. 31, no. 2, pp. 346-356, 2013.

[95] R. R. R. Kannan, W. A. Stirk, and J. Van Staden, "Synthesis of silver nanoparticles using the seaweed Codium capitatum P.C. Silva (Chlorophyceae)," South African Journal of Botany, vol. 86, pp. 1-4, 2013.

[96] L. Castro, M. L. Blázquez, J. A. Muñoz, F. González, and A. Ballester, "Biological synthesis of metallic nanoparticles using algae," IET Nanobiotechnology, vol. 7, no. 3, pp. 109-116, 2013.

[97] K. F. Princy and A. Gopinath, "Eco-friendly synthesis and characterization of silver nanoparticles using marine macroalga Padina tetrastromatica," International Journal of Science and Research, vol. 4, no. 6, pp. 1050-1054, 2015.

[98] G. Singaravelu, J. S. Arockiamary, V. G. Kumar, and K. Govindaraju, "A novel extracellular synthesis of monodisperse gold nanoparticles using marine alga, Sargassum wightii Greville," Colloids and Surfaces B: Biointerfaces, vol. 57, no. 1, pp. 97-101, 2007.

[99] S. Rajeshkumar, C. Malarkodi, G. Gananajobitha et al., "Seaweed-mediated synthesis of gold nanoparticles using Turbinaria conoides and its characterization," Journal of Nanostructure in Chemistry, vol. 3, no. 44, pp. 1-7, 2013.

[100] F. Arockiya Aarthi Rajathi, C. Parthiban, V. Ganesh Kumar, and P. Anantharaman, "Biosynthesis of antibacterial gold nanoparticles using brown alga, Stoechospermum marginatum (kützing)," Spectrochimica Acta - Part A: Molecular and Biomolecular Spectroscopy, vol. 99, pp. 166-173, 2012.

[101] E. Eroglu, X. Chen, M. Bradshaw et al., "Biogenic production of palladium nanocrystals using microalgae and their immobilization on chitosan nanofibers for catalytic applications," RSC Advances, vol. 3, no. 4, pp. 1009-1012, 2013.

[102] H. L. Parker, J. R. Dodson, V. L. Budarin, J. H. Clark, and A. J. Hunt, "Direct synthesis of Pd nanoparticles on alginic acid and seaweed supports," Green Chemistry, vol. 17, no. 4, pp. 22002207, 2015.

[103] Y. Abboud, T. Saffaj, A. Chagraoui et al., "Biosynthesis, characterization and antimicrobial activity of copper oxide nanoparticles (CONPs) produced using brown alga extract (Bifurcaria bifurcata)," Applied Nanoscience, vol. 4, no. 5, pp. 571-576, 2014.

[104] H. Khanehzaei, M. B. Ahmad, K. Shameli, and Z. Ajdari, "Synthesis and characterization of $\mathrm{Cu} @ \mathrm{Cu} 2 \mathrm{O}$ core shell nanoparticles prepared in seaweed kappaphycus alvarezii media," International Journal of Electrochemical Science, vol. 9, no. 12, pp. 81898198, 2014.

[105] S. Azizi, M. B. Ahmad, F. Namvar, and R. Mohamad, "Green biosynthesis and characterization of zinc oxide nanoparticles using brown marine macroalga Sargassum muticum aqueous extract," Materials Letters, vol. 116, pp. 275-277, 2014.

[106] M. Francavilla, A. Pineda, A. A. Romero et al., "Efficient and simple reactive milling preparation of photocatalytically active porous $\mathrm{ZnO}$ nanostructures using biomass derived polysaccharides," Green Chemistry, vol. 16, no. 5, pp. 2876-2885, 2014.

[107] S. Rajeshkumar, C. Kannan, and G. Amnadurai, "Synthesis and characterization of antimicrobial silver nanoparticles using marine brown seaweed Padina tetrastromatica," Drug Invention Today, vol. 4, no. 10, pp. 511-513, 2012.

[108] M. Vivek, P. Senthil Kumar, S. Steffi, and S. Sudha, "Biogenic silver nanoparticles by Gelidiella acerosa extract and their antifungal effects," Avicenna Journal of Medical Biotechnology, vol. 3, no. 3, pp. 143-148, 2011. 
[109] K. Govindaraju, V. Kiruthiga, V. G. Kumar, and G. Singaravelu, "Extracellular synthesis of silver nanoparticles by a marine alga, Sargassum wightii grevilli and their Antibacterial effects," Journal of Nanoscience and Nanotechnology, vol. 9, no. 9, pp. 5497-5501, 2009.

[110] J. Suriya, S. Bharathi Raja, V. Sekar, and R. Rajasekaran, "Biosynthesis of silver nanoparticlesand its antibacterial activity using seaweed Urospora sp," African Journal of Biotechnology, vol. 11, no. 58, pp. 12192-12198, 2012.

[111] N. Sangeetha and K. Saravanan, "Biogenic silver nanoparticles using marine seaweed (Ulva lactuca) and evaluation of its antibacterial activity," Journal of Nanoscience and Nanotechnology, vol. 2, no. 1, pp. 99-102, 2014.

[112] M. Yousefzadi, Z. Rahimi, and V. Ghafori, "The green synthesis, characterization and antimicrobial activities of silver nanoparticles synthesized from green alga Enteromorpha flexuosa (wulfen) J. Agardh," Materials Letters, vol. 137, pp. 1-4, 2014.

[113] N. Shanmugam, P. Rajkamal, S. Cholan et al., "Biosynthesis of silver nanoparticles from the marine seaweed Sargassum wightii and their antibacterial activity against some human pathogens," Applied Nanoscience, vol. 4, no. 7, pp. 881-888, 2014.

[114] N. Thangaraju, R. P. Venkatalakshmi, A. Chinnasamy, and P. Kannaiyan, "Synthesis of silver nanoparticles and the antibacterial and anticancer activities of the crude extract of Sargassum polycystum C. Agardh," Nano Biomedicine and Engineering, vol. 4, no. 2, pp. 89-94, 2012.

[115] S. R. Vijayan, P. Santhiyagu, N. K. Ahila, R. Jayaraman, and K. Ethiraj, "Synthesis and characterization of silver and gold nanoparticles using aqueous extract of seaweed, Turbinaria conoides, and their Antimicrofouling activity", The Scientific World Journal, vol. 2014, Article ID 938272, 10 pages, 2014.

[116] T. Stalin Dhas, V. Ganesh Kumar, V. Karthick, K. Jini Angel, and K. Govindaraju, "Facile synthesis of silver chloride nanoparticles using marine alga and its antibacterial efficacy," Spectrochimica Acta-Part A: Molecular and Biomolecular Spectroscopy, vol. 120, pp. 416-420, 2014.

[117] I. Geethu and R. Emilin Renitta, "Brown Algae mediated synthesis, characterization of gold nano particles using Padina pavonica and their antibacterial activity against human pathogens," International Journal of PharmTech Research, vol. 8, no. 9, pp. 31-40, 2015.

[118] V. Patel, D. Berthold, P. Puranik, and M. Gantar, "Screening of cyanobacteria and microalgae for their ability to synthesize silver nanoparticles with antibacterial activity," Biotechnology Reports, vol. 5, no. 1, pp. 112-119, 2015.

[119] N. Asmathunisha and K. Kathiresan, "A review on biosynthesis of nanoparticles by marine organisms," Colloids and Surfaces B: Biointerfaces, vol. 103, pp. 283-287, 2013.

[120] C. Sicard, R. Brayner, J. Margueritat et al., "Nano-gold biosynthesis by silica-encapsulated micro-algae: a 'living' bio-hybrid material," Journal of Materials Chemistry, vol. 20, no. 42, pp. 9342-9347, 2010.

[121] X. Chen and H. J. Schluesener, "Nanosilver: a nanoproduct in medical application," Toxicology Letters, vol. 176, no. 1, pp. 1-12, 2008.

[122] G. A. Sotiriou and S. E. Pratsinis, "Engineering nanosilver as an antibacterial, biosensor and bioimaging material," Current Opinion in Chemical Engineering, vol. 1, no. 1, pp. 3-10, 2011.

[123] S. M. Hussain, K. L. Hess, J. M. Gearhart, K. T. Geiss, and J. J. Schlager, "In vitro toxicity of nanoparticles in BRL 3A rat liver cells," Toxicology in Vitro, vol. 19, no. 7, pp. 975-983, 2005.
[124] J. K. Vasir and V. Labhasetwar, "Quantification of the force of nanoparticle-cell membrane interactions and its influence on intracellular trafficking of nanoparticles," Biomaterials, vol. 29, no. 31, pp. 4244-4252, 2008.

[125] Y. Mikami, A. Dhakshinamoorthy, M. Alvaro, and H. García, "Catalytic activity of unsupported gold nanoparticles," Catalysis Science and Technology, vol. 3, no. 1, pp. 58-69, 2013.

[126] E. Torres-Chavolla, R. J. Ranasinghe, and E. C. Alocilja, "Characterization and functionalization of biogenic gold nanoparticles for biosensing enhancement," IEEE Transactions on Nanotechnology, vol. 9, no. 5, pp. 533-538, 2010.

[127] Y. Zhao, Y. Tian, Y. Cui, W. Liu, W. Ma, and X. Jiang, "Small molecule-capped gold nanoparticles as potent antibacterial agents that target gram-negative bacteria," Journal of the American Chemical Society, vol. 132, no. 35, pp. 12349-12356, 2010.

[128] P. Puvanakrishnan, J. Park, D. Chatterjee, S. Krishnan, and J. W. Tunnell, "In vivo tumor targeting of gold nanoparticles: effect of particle type and dosing strategy," International Journal of Nanomedicine, vol. 7, pp. 1251-1258, 2012.

[129] W. Cai, T. Gao, H. Hong, and J. Sun, "Applications of gold nanoparticles in cancer nanotechnology," Nanotechnology, Science and Applications, vol. 1, pp. 17-32, 2008.

[130] P. Ghosh, G. Han, M. De, C. K. Kim, and V. M. Rotello, "Gold nanoparticles in delivery applications," Advanced Drug Delivery Reviews, vol. 60, no. 11, pp. 1307-1315, 2008.

[131] T. Luangpipat, I. R. Beattie, Y. Chisti, and R. G. Haverkamp, "Gold nanoparticles produced in a microalga," Journal of Nanoparticle Research, vol. 13, no. 12, pp. 6439-6445, 2011.

[132] P. Rajasulochana, R. Dhamotharan, P. Murugakoothan, S. Murugesan, and P. Krishnamoorthy, "Biosynthesis and characterization of gold nanoparticles using the alga Kappaphycus alvarezii," International Journal of Nanoscience, vol. 9, no. 5, pp. 511-516, 2010.

[133] S. Senapati, A. Syed, S. Moeez, A. Kumar, and A. Ahmad, "Intracellular synthesis of gold nanoparticles using alga Tetraselmis kochinensis," Materials Letters, vol. 79, pp. 116-118, 2012.

[134] T. Ashokkumar and K. Vijayaraghavan, "Brown seaweedmediated biosynthesis of gold nanoparticles," Journal of Environment and Biotechnology Research, vol. 2, no. 1, pp. 45-50, 2016.

[135] B. Sharma, D. D. Purkayastha, S. Hazra et al., "Biosynthesis of gold nanoparticles using a freshwater green alga, Prasiola crispa," Materials Letters, vol. 116, pp. 94-97, 2014.

[136] B. Sharma, D. D. Purkayastha, S. Hazra et al., "Biosynthesis of fluorescent gold nanoparticles using an edible freshwater red alga, Lemanea fluviatilis (L.) C.Ag. and antioxidant activity of biomatrix loaded nanoparticles," Bioprocess and Biosystems Engineering, vol. 37, no. 12, pp. 2559-2565, 2014.

[137] G. Scarano and E. Morelli, "Properties of phytochelatin-coated CdS nanocrystallites formed in a marine phytoplanktonic alga (Phaeodactylum tricornutum, Bohlin) in response to Cd," Plant Science, vol. 165, no. 4, pp. 803-810, 2003.

[138] T. Zhai, X. Fang, M. Liao et al., "A comprehensive review of one-dimensional metal-oxide nanostructure photodetectors," Sensors, vol. 9, no. 8, pp. 6504-6529, 2009.

[139] M. Srivastava, J. Singh, R. K. Mishra, and A. K. Ojha, "Electrooptical and magnetic properties of monodispersed colloidal $\mathrm{Cu}_{2} \mathrm{O}$ nanoparticles," Journal of Alloys and Compounds, vol. 555, pp. 123-130, 2013.

[140] N. Ramgir, N. Datta, M. Kaur et al., "Metal oxide nanowires for chemiresistive gas sensors: issues, challenges and prospects," 
Colloids and Surfaces A: Physicochemical and Engineering Aspects, vol. 439, pp. 101-116, 2013.

[141] C. D. Montferrand, L. Hu, I. Milosevic et al., "Iron oxide nanoparticles with sizes, shapes and compositions resulting in different magnetization signatures as potential labels for multiparametric detection," Acta Biomaterialia, vol. 9, no. 4, pp. 6150-6157, 2013.

[142] S. J. Ahmadi, M. Outokesh, M. Hosseinpour, and T. Mousavand, "A simple granulation technique for preparing high-porosity nano copper oxide (II) catalyst beads," Particuology, vol. 9, no. 5, pp. 480-485, 2011.

[143] F. Namvar, H. S. Rahman, R. Mohamad et al., "Cytotoxic effect of magnetic iron oxide nanoparticles synthesized via seaweed aqueous extract," International Journal of Nanomedicine, vol. 9, no. 1, pp. 2479-2488, 2014.

[144] P. Sudhagar, R. S. Kumar, J. H. Jung et al., "Facile synthesis of highly branched jacks-like $\mathrm{ZnO}$ nanorods and their applications in dye-sensitized solar cells," Materials Research Bulletin, vol. 46, no. 9, pp. 1473-1479, 2011.

[145] S. Cho, S. Kim, J.-W. Jang et al., "Large-scale fabrication of sub20-nm-diameter $\mathrm{ZnO}$ nanorod arrays at room temperature and their photocatalytic activity," The Journal of Physical Chemistry C, vol. 113, no. 24, pp. 10452-10458, 2009.

[146] A. Sapkota, A. J. Anceno, S. Baruah, O. V. Shipin, and J. Dutta, "Zinc oxide nanorod mediated visible light photoinactivation of model microbes in water," Nanotechnology, vol. 22, no. 21, 2011.

[147] F. Namvar, H. S. Rahman, R. Mohamad et al., "Cytotoxic effects of biosynthesized zinc oxide nanoparticles on murine cell lines," Evidence-Based Complementary and Alternative Medicine, vol. 2015, Article ID 593014, 11 pages, 2015.

[148] R. Van Horssen, T. L. M. Ten Hagen, and A. M. M. Eggermont, "TNF- $\alpha$ in cancer treatment: molecular insights, antitumor effects, and clinical utility," Oncologist, vol. 11, no. 4, pp. 397-408, 2006.

[149] L. R. Hirsch, R. J. Stafford, J. A. Bankson et al., "Nanoshellmediated near-infrared thermal therapy of tumors under magnetic resonance guidance," Proceedings of the National Academy of Sciences of the United States of America, vol. 100, no. 23, pp. 13549-13554, 2003.

[150] Y. Zheng and L. Sanche, "Gold nanoparticles enhance DNA damage induced by anti-cancer drugs and radiation," Radiation Research, vol. 172, no. 1, pp. 114-119, 2009.

[151] C. C. Berry and A. S. G. Curtis, "Functionalisation of magnetic nanoparticles for applications in biomedicine," Journal of Physics D: Applied Physics, vol. 36, no. 13, pp. R198-R206, 2003. 

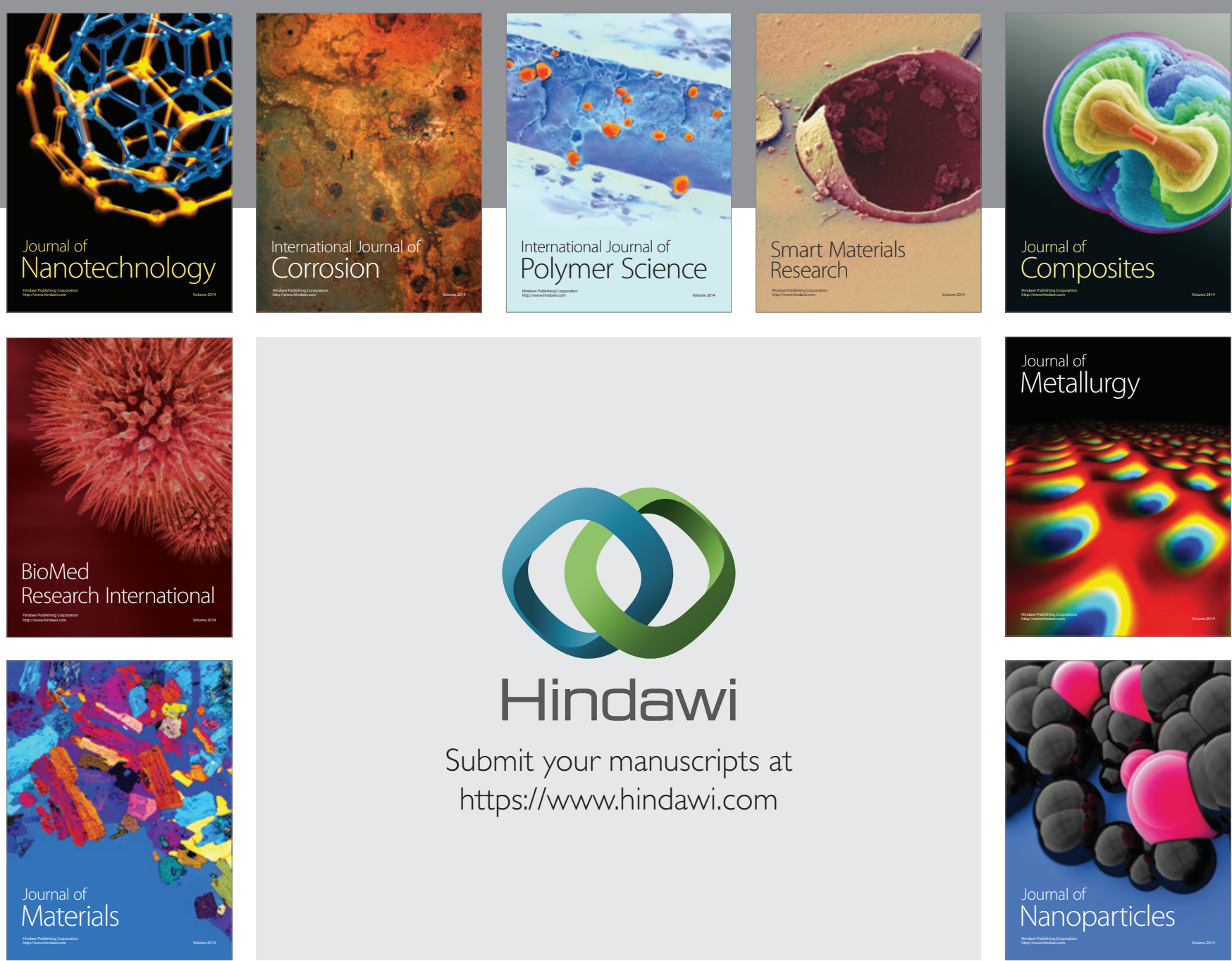

\section{Hindawi}

Submit your manuscripts at

https://www.hindawi.com

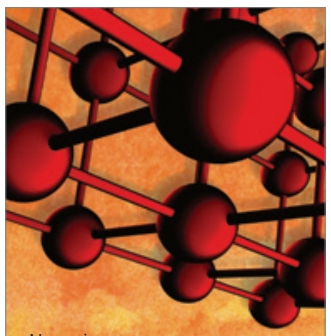

Materials Science and Engineering
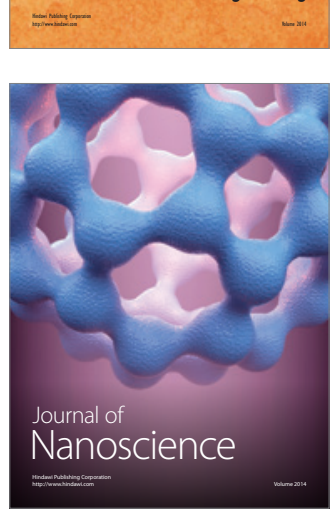
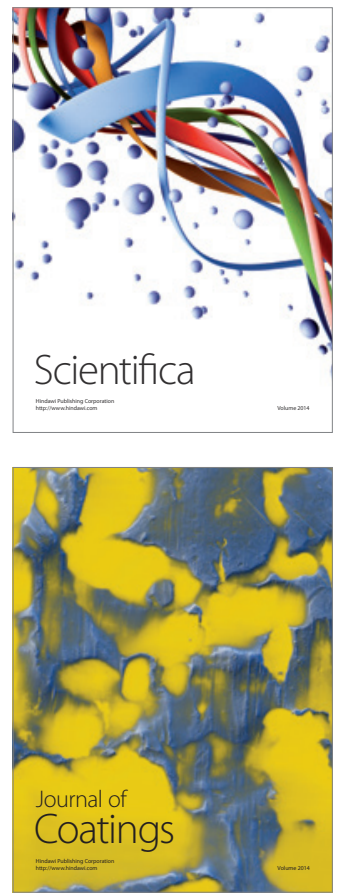
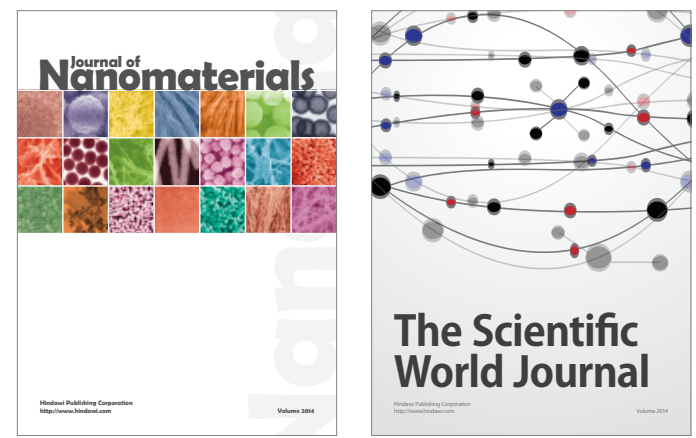

The Scientific World Journal
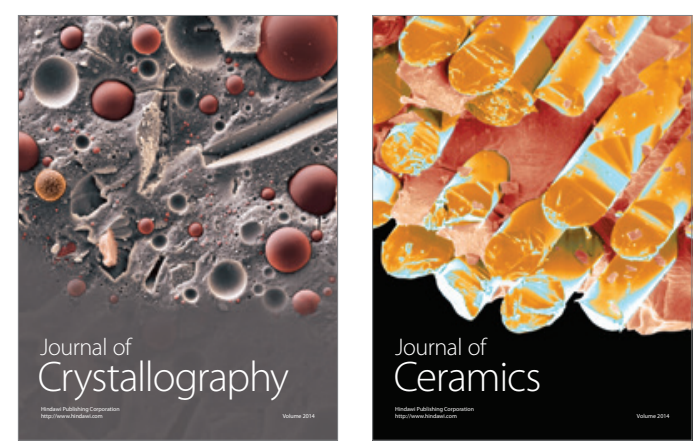
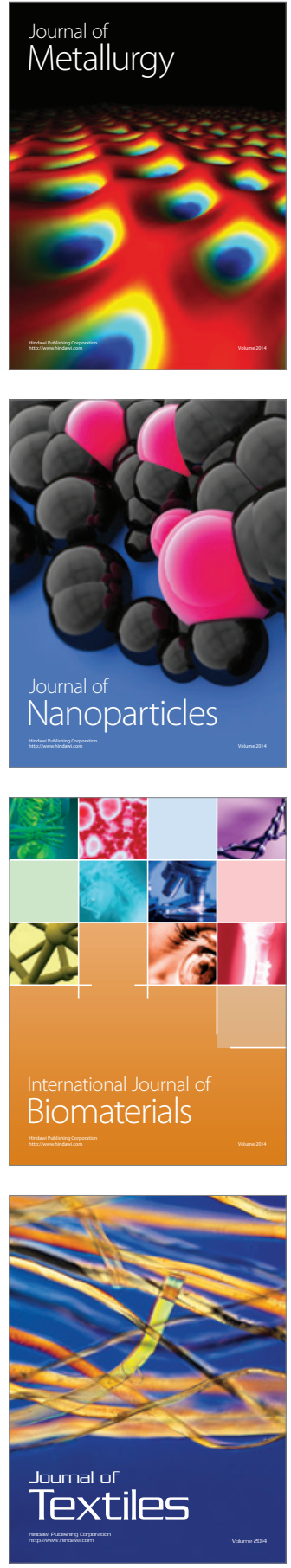